

\title{
Boron-Doped Graphene-Supported Manganese Oxide Nanotubes as ar Article Online Efficient Non-Metal Catalyst for Oxygen Reduction Reaction
}

\author{
M. Sookhakian ${ }^{*} a, b$, Habib Ullah ${ }^{c}$, Mohd Asri Mat Teridid, Goh Boon Tong ${ }^{b}$, W. J. \\ Basirunf, Y. Alias ła,e
}

aUniversity Malaya Centre for Ionic Liquids, Department of Chemistry, Faculty of Science, University of Malaya, Kuala Lumpur 50603, Malaysia.

bLow Dimensional Materials Research Centre, Department of Physics, Faculty of Science, University of Malaya, 50603 Kuala Lumpur, Malaysia.

'Renewable Energy Group, College of Engineering, Mathematics and Physical Sciences, University of Exeter, Penryn Campus, Cornwall, TR10 9FE, United Kingdom.

dSolar Energy Research Institute (SERI), University Kebangsaan Malaysia, 43600 UKM Bangi, Selangor, Malaysia

eDepartment of Chemistry, Faculty of Science, University of Malaya, Kuala Lumpur 50603, Malaysia.

fInstitute of Nanotechnology \& Catalysis Research, Institute of Postgraduate Studies, University Malaya, 50603 Kuala Lumpur, Malaysia.

\footnotetext{
*Corresponding authors: Tel/Fax: +603-79675538. E-mail addresses: m.sokhakian@um.edu.my (M. Sookhakian)

${ }^{+}$Corresponding authors: Tel/Fax: +603-79675538. E-mail addresses: yatimah70@um.edu.my (Y. Alias)
} 


\section{Abstract}

An efficient, low cost and non-precious hybrid metal catalyst compound, consisting of boron-doped graphene nanosheets (BGNS) and manganese oxide nanotube $\left(\mathrm{MnO}_{2}\right)$ is used as a catalyst for oxygen reduction reaction (ORR). The morphological, chemical composition and electrochemical properties of the as-synthesized BGNS- $\mathrm{MnO}_{2}$ composite $\left(\mathrm{MnO}_{2} @ \mathrm{BGNS}\right)$ were characterized using transmission electron microscopy, X-ray photoelectron spectroscopy, Raman spectroscopy, linear sweep voltammetry and rotating disk electrode (RDE). The asprepared BGNS- $\mathrm{MnO}_{2}$-modified glassy carbon electrode (GCE) displayed excellent catalytic activity towards ORR in an alkaline medium compared to the pure $\mathrm{MnO}_{2}$ and pure BGNS. In addition, the hybrid electrode exhibited superior electrocatalytic stability and preferable methanol tolerance compared to commercial platinum electrocatalyst in an alkaline media. This is due to the synergistic effect between the excellent catalytic activity of the $\mathrm{MnO}_{2}$ nanotubes and the large surface area and high conductivity of BGNS. Moreover, density functional theory (DFT) calculations show a strong binding energy between BGNS and $\mathrm{MnO}_{2}$ in the form of strong electrostatic interaction and inter charge transfer. The enhanced reactivity of $\mathrm{MnO}_{2} @ \mathrm{BGNS}$ is due to the strong bonding between the boron (BGNS) and oxygen $\left(\mathrm{MnO}_{2}\right)$. Moreover, the electron density difference and partial density of state (PDOS) analysis suggest that the electron transfer capability of $\mathrm{B}-\mathrm{O}$ bonding is stronger than the $\mathrm{C}-\mathrm{O}$ bonding. Finally, we conclude that boron doping of graphene is an effective strategy for fabricating an efficient ORR catalysts.

Keywords: Boron doped graphene; Manganese oxide; Oxygen reduction reaction; methanol interferent; Alkaline medium. 


\section{Introduction}

Oxygen reduction reaction (ORR) in alkaline media is one of the most important electrocatalytic reactions, which has significant application in many green energy technologies especially in metal-air batteries and fuel cells. However, ORR suffers from high overpotential, intolerance to fuel crossover and a sluggish ORR kinetics at the cathode, which results in poor performance and commercialization of fuel cells and batteries ${ }^{1}$. Ideally, the cathode catalyst consists of platinum $(\mathrm{Pt})$ and $\mathrm{Pt}$-based alloy due to the high electrocatalytic activity and stability. Moreover, other noble metal electrocatalyst such as palladium (Pd) and its alloys were successfully applied and showed good catalytic activity towards ORR ${ }^{2}$. However, noble metal catalyst and their alloys suffer from major drawbacks of agglomeration and dissolution during cell operation, as well as low abundance in nature, high cost and low efficiency in the presence of side reactions such as methanol oxidation which occurs in direct methanol fuel cells ${ }^{1}$. Therefore, greater attention has been devoted to explore non-noble metal catalytic materials with high performance and good durability for ORR.

Currently, non-noble metal catalysts such as transition metal sulfides, oxides, perovskites and carbonaceous materials have attracted increasing attention in ORR. Among the non-noble metal catalyst, manganese oxides $\left(\mathrm{MnO}_{2}\right)$ have recently attracted much attention as a promising substitute for noble metal catalysts in the ORR due to the high electrocatalytic activity, non-toxicity, easy preparation and lower cost ${ }^{3}$. Recently, $\mathrm{MnO}_{2}$ nanostructures with different morphology such as nanoparticles ${ }^{4}$, nanowire ${ }^{5}$, nanosheets ${ }^{6}$, and nanorods ${ }^{7}$ have been synthesized by different methods. Theoretical calculations and experimental results have reported that the catalytic activity of $\mathrm{MnO}_{2}$ nanostructures strongly depend on the shape, porosity, crystallinity 


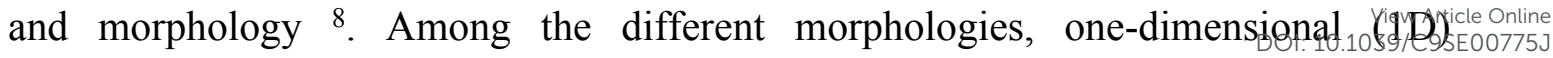
nanostructures especially nanotubes are beneficial for ORR because they have ideal geometrical structures to provide a direct pathway for charge transport ${ }^{9}$. Therefore, the rate of charge transport through the direct electrical channel of the nanotube structure is expected to be faster than other morphologies, which results in the improvement of the ORR activity ${ }^{9}$. However, the high resistance contact between the $\mathrm{MnO}_{2}$ nanostructures and conducting electrode such as glassy carbon electrode (GCE) is another main challenge. This leads to an increase in the charge carrier recombination in the $\mathrm{MnO}_{2}$ structures, which results in the poor interaction between the electrode and electrolyte, thus decreases the overall electrocatalytic performance of the ORR ${ }^{10}$. Therefore, to overcome this challenge, the modification of nanostructured catalyst using conducting polymers (polypyrrole and polyaniline) and nanocarbons such as carbon nanotubes, carbon nanospheres and graphene have been utilized to increase the conductivity of the ORR electrocatalyst and their surface area which enhances the electrocatalytic activity and stability of the ORR catalysts ${ }^{11}$.

Graphene nanosheets (GNS), a two-dimensional material with $\mathrm{sp}^{2}$ hybridized network of carbon atoms, is a novel support material due to its excellent physical and chemical properties such as high carrier mobility, excellent electrical conductivity, high chemical stability, high surface area and strong interfacial adhesion with electrocatalytic materials. GNS are almost transparent and has great potential in many applications such as solar cell ${ }^{12}$, sensors ${ }^{13}$, energy storage applications ${ }^{14}$ and ORR ${ }^{15}$. The modification of the catalyst nanostructures with GNS leads to enhanced performance of the ORR. This is due to the excellent electrical conductivity of GNS which increases the electron transfer rate of the catalyst nanostructures between the conductive electrodes and electrolytes ${ }^{15}$. However, the aggregation of GNS due to the 
strong van der Waals forces between the nanosheets during the reduction process synthesis of the electrocatalyst composites is the major challenge. This effect decreases the conductivity and surface area of the GNS. To overcome this challenge, doping of the GNS lattice with heteroatoms is an effective strategy, which not only prevents the aggregation of GNS but also modulates the electronic structure and physicochemical properties of GNS. Among various heteroatoms, boron (B) and nitrogen $(\mathrm{N})$ are the best dopants due to their similar atomic radius, which facilitates bonding with carbon atoms. Theoretical and experimental studies have revealed that $\mathrm{N}$ - and B-doping into GNS lattice turns them into n-type and p-type semiconductors, respectively 1316 . Moreover, the vacant orbital of the B atom with the $\pi$ electrons of GNS can form strong valence bonds, and consequently tune the electronic and mechanical properties of GNS. This leads to a fast nucleation process and uniform decoration of the catalyst nanostructures. In addition, the presence of the vacant orbital due to the conjugation of B atoms with the $\pi$ electrons in the GNS lattice can be activated for the catalytic reduction of oxygen molecules on the positively charged boron sites. Therefore, the electroneutrality of $\mathrm{sp}^{2}$ carbons in GNS could be broken with the presence of the electron-deficient $\mathrm{B}$ dopants, resulting in presence of favorable sites for $\mathrm{O}_{2}$ adsorption and reduction, which is beneficial for the increased catalytic performance of the ORR 16.

Herein, we report the synthesis of boron doped graphene nanosheets (BGNS) supported $\mathrm{MnO}_{2}$ nanotube $\left(\mathrm{MnO}_{2} @ \mathrm{BGNS}\right)$ hybrid via a facile and effective hydrothermal assisted process. The BGNS was synthesized via the thermal annealing of graphene oxide (GO) with boric acid at $700{ }^{\circ} \mathrm{C}$. The $1 \mathrm{D}$ morphology of the $\mathrm{MnO}_{2}$ nanotubes and a porous structure of BGNS, with high surface area and active sites enhances the activity and stability of the ORR. In addition, the experimental results are 
counterchecked with the help of density functional theory simulations. It was found diffhaticle Online the BGNS forms strong bonding with the surface atoms of $\mathrm{MnO}_{2}$, whereby the BGNS donates the electron density to $\mathrm{MnO}_{2}$ and forms the $\pi$ conjugation. This inter-charge transfer and high interaction between the two materials results in a stable and efficient $\mathrm{MnO}_{2} @$ BGNS ORR catalyst.

\section{Experimental methods}

\subsection{Chemical reagents}

Analytical grade chemicals i.e., potassium permanganate $\left(\mathrm{KMnO}_{4}\right)$, potassium hydroxide $(\mathrm{KOH})$, hydrochloric acid $(36 \mathrm{wt} \% \mathrm{HCl})$, graphite flakes $(1-2 \mu \mathrm{m})$, and boric acid $\left(\mathrm{H}_{3} \mathrm{BO}_{3}\right)$ were purchased from Sigma Aldrich, were of analytical grade and dissolved in double-distilled water. Pt (20\%) on carbon $(20 \mathrm{wt} \% \mathrm{Pt} / \mathrm{C}$, and diameter of $5 \mathrm{~nm})$ was purchased from Johnson Matthey Corporation. All experiments were conducted at atmospheric pressure.

\subsection{Synthesis of BGNS and GNS}

Graphene oxide (GO) was synthesized from natural graphite flakes using the modified Hummers method ${ }^{17}$. BGNS was prepared by a thermal solid-state reaction of GO and boric acid. In a typical experiment, $300 \mathrm{mg}$ of GO and $900 \mathrm{mg}$ boric acid with a mass ratio of 1:3 was dispersed in deionized water under sonication for $5 \mathrm{~h}$. After the mixture was freeze-dried, the solid mixture was ground in a mortar to produce a homogenous mixture. The homogenous mixture was then placed at the center of a quartz boat container and subsequently placed in a horizontal tube furnace. Pure argon gas with a flow rate of $100 \mathrm{sccm}$ was used to remove oxygen gas from the tube furnace. The temperature of the furnace was gradually increased to $700{ }^{\circ} \mathrm{C}$ at a rate of $5{ }^{\circ} \mathrm{C} \mathrm{min}^{-1}$ 
for $2 \mathrm{~h}$. Then, the powder was allowed to cool to room temperature. The as-synthesjevedicte Online BGNS were ground and washed with ethyl alcohol and distilled water 3 times before dried at $60{ }^{\circ} \mathrm{C}$ for $12 \mathrm{~h}$. GNS was synthesized using the same procedure but with the absence of the boric acid.

\subsection{Synthesis of $\mathrm{MnO}_{2} @ B G N S$ composite and pure $\mathrm{MnO}_{2}$ nanotube}

$\mathrm{MnO}_{2} @ \mathrm{BGNS}$ composite was synthesized by the hydrothermal method using the precursors of BGNS, potassium permanganate and hydrochloric acid. In a typical procedure, $65.8 \mathrm{mg}$ BGNS and $658 \mathrm{mg} \mathrm{KMnO}_{4}$ in $40 \mathrm{ml}$ of distilled water was first stirred and sonicated for $35 \mathrm{~min}$, respectively, to achieve an electrostatic adsorption of the manganese ions onto the BGNS, followed by the dropwise addition of $1.5 \mathrm{ml}$ concentrated $\mathrm{HCl}(36 \%)$ into the suspension by stirring for $15 \mathrm{~min}$. Finally, the homogenous suspension was sealed tightly in a 60 $\mathrm{ml}$ Teflon-lined autoclave and heated at $150{ }^{\circ} \mathrm{C}$ for $12 \mathrm{~h}$. The as-synthesized $\mathrm{MnO}_{2} @ \mathrm{BGNS}$ composite was washed with ethyl alcohol and distilled water 3 times and dried at $60{ }^{\circ} \mathrm{C}$ for $12 \mathrm{~h}$. For comparison, pure $\mathrm{MnO}_{2}$ nanotubes were also prepared via the same procedure but in the absence of BGNS. The experimental procedure was performed more than ten times and it was reproducible.

\subsection{Characterization}

The crystal structure and morphology of the samples were investigated by X-ray powder diffractometer (XRD, PANalytical Empyrean) with a monochromated $\mathrm{Cu} \mathrm{Ka}$ radiation $(\mathrm{l}=1.54056 \AA)$ and high resolution transmission electron microscope $(500 \mathrm{kV}$, HR-TEM-FEIG-4020). The as-synthesized powders were sonicated in double-distilled 
water prior to the HR-TEM characterization. Raman spectroscopic analysis Jyas calyjivedicle Online out using Invia Raman Microscope instrument (laser excitation, $1=514 \mathrm{~nm}$ ) while Xray photoelectron spectroscopy (XPS) analysis was performed using an ESCALAB MK II X-ray photoelectron spectrometer (Mg excitation source). Nitrogen adsorption and desorption were determined at $77 \mathrm{~K}$ with a Micromeritics Tristar 4000 analyzer instrument. Electrochemical measurements such as cyclic voltammograms (CVs), electrochemical impedance spectroscopy (EIS), linear sweep voltammetry, rotating ring-disk electrode (RRDE: glassy carbon disk $(5 \mathrm{~mm})$ and Pt ring $(375 \mu \mathrm{m}))$ and rotating disk electrode (RDE) were measured by potentiostat/galvanostat (Autolab PGSTAT30, Ecochemie Netherlands) in a three-electrode cell system. A polished glassy carbon electrode (GCE) modified with the as-synthesized samples was utilized as the working electrode, while an $\mathrm{Ag} / \mathrm{AgCl}$ and a graphite rod was the reference electrode and counter electrode, respectively. The ORR experiment was conducted in $\mathrm{O}_{2}$ saturated 0.1 M KOH electrolyte.

\subsection{Electrode preparation}

The catalyst ink was prepared by dispersion of $5 \mathrm{mg}$ of the catalyst into 5 $\mathrm{mL}$ solvent mixture of Nafion (5\%) and distilled water with a volume ratio of 1:9 for 30 min under sonication. Then, $10 \mu \mathrm{l}$ of the catalyst suspension was dropcasted onto a polished GCE surface and then dried overnight at $50{ }^{\circ} \mathrm{C}$ prior to the ORR measurement. The Pt loading on the GCE was $\sim 15 \mu \mathrm{g} \mathrm{cm}^{-2}$. More than 50 electrodes were prepared and they were almost reproducible.

\subsection{Computational Methodology}


The periodic density functional theory (DFT) calculations were performedg Quantum- Wise ATK ${ }^{18}$ and the results were visualized by Virtual NanoLab Version 2018.1 ${ }^{1819}$. The $\mathrm{MnO}_{2}$ nanotube crystallizes in the tetragonal $\mathrm{I} / \mathrm{m}$ space group. The structure is three-dimensional, where the $\mathrm{Mn}^{4+}$ is bonded to six $\mathrm{O}^{2-}$ atoms to form a mixture of edge and corner sharing $\mathrm{MnO}^{6}$ octahedra. The $\mathrm{Mn}-\mathrm{O}$ bond distances is between 1.92-1.95 $\AA$. There are two inequivalent $\mathrm{O}^{2-}$ sites, the first is the $\mathrm{O}^{2-}$ bonded in a distorted trigonal planar geometry to three equivalent $\mathrm{Mn}^{4+}$ atoms, while the second $\mathrm{O}^{2-}$ site is bonded in a distorted trigonal non-coplanar geometry to three equivalent $\mathrm{Mn}^{4+}$ atoms. After optimizing the lattice parameters of the bulk unit cell; a supercell (1x1x3) was constructed, from which the (001) $\mathrm{MnO}_{2}$ slab was built. Herein the (001) $\mathrm{MnO}_{2}$ represents the $\mathrm{MnO}_{2}$. The thickness of the slab was kept as three primitive unit cells of $\mathrm{MnO}_{2}\left(10 \AA\right.$ thickness having 72 atoms). The (001) termination of $\mathrm{MnO}_{2}$ possesses low surface energy and as a result represents the most probable surface termination. The stability of these different slabs are confirmed from their positive surface formation energy and electrostatic potential. The single layer of GNS and BGNS are selected for the simulations. The structure of the single layer of GNS and BGNS are illustrated (vide infra). Generalized gradient approximation (GGA) with the Perdew-Burke-Ernzerhof (PBE) exchange-correlation functional and double Zeta Polarized (DZP) basis set was used for the structural and energy optimization due to its superiority over hybrid pseudopotentials ${ }^{19}$. The linear combination of atomic orbitals (LCAO) method is used for the Mn, C, B and $\mathrm{O}$ atoms ${ }^{19}$. A 5x5x1 Monkhorst-Pack kgrid with an energy cut-off of $700 \mathrm{eV}$ was used for the $\mathrm{MnO}_{2}$ unit cell, while a $5 \mathrm{x} 5 \mathrm{x} 1$ k-point mesh was used as the slabs. A 7x7x7 Monkhorst-Pack k-grid and energy cutoff of $500 \mathrm{eV}$ was used for the monolayer GNS and BGNS, while a 5x5x1 k-point mesh with $700 \mathrm{eV}$ cut-off energy was used for the $\mathrm{MnO}_{2} @$ GNS and $\mathrm{MnO}_{2} @ \mathrm{BGNS}$ 
heterostructures. The density of states (DOS), partial density of states (PDOS), eledectiventicle Online density difference (EDD) and electron localization functional (ELF) calculations were performed with a TB09LDA functional of meta-GGA, which can accurately reproduce the experimental bandgaps. Recently, Tran and Blaha ${ }^{20}$ reported that this accuracy is due to the local density $\rho(\mathrm{r})$ (as in LDA), the gradient of density $\nabla \rho(\mathrm{r})$ (as in GGA), and the kinetic-energy density $\tau(r)$.

\section{Results and discussions}

\subsection{Characterization}

Fig. 1 shows the XRD patterns of pure $\mathrm{MnO}_{2}$ nanotubes and $\mathrm{MnO}_{2} @ \mathrm{BGNS}$ composite after the hydrothermal process. The XRD pattern of $\mathrm{MnO}_{2}$ nanotubes exhibited high intensity peaks at $2 \theta=12.682^{\circ}, 17.986^{\circ}, 25.608^{\circ}, 28.646^{\circ}, 36.480^{\circ}$, $37.486^{\circ}, 38.916^{\circ}, 41.126^{\circ}, 41.906,49.788^{\circ}, 56.310^{\circ}, 60.210^{\circ}, 65.306^{\circ}, 69.648^{\circ}$, and $72.828^{\circ}$, can be well indexed to the (110), (200), (220), (310), (400), (121), (330), (431), (301), (411), (600), (521), (002), (541), and (312) lattice planes, respectively, of tetragonal phase of $\mathrm{MnO}_{2}$ nanotubes (JCPDS card no. 01-072-1982) with the lattice constants of $\mathrm{a}=\mathrm{b}=\mathrm{c}=3.923 \AA^{21}$. Remarkably, the $\mathrm{MnO}_{2} @$ BGNS composite exhibited XRD pattern similar to those of the blank $\mathrm{MnO}_{2}$ nanotubes i.e. no diffraction peaks were present between $20^{\circ}$ to $30^{\circ}$, indicating that the $\mathrm{MnO}_{2}$ nanotubes were efficiently decorated on the surface of BGNS, which prevented the BGNS from stacking and agglomeration. 


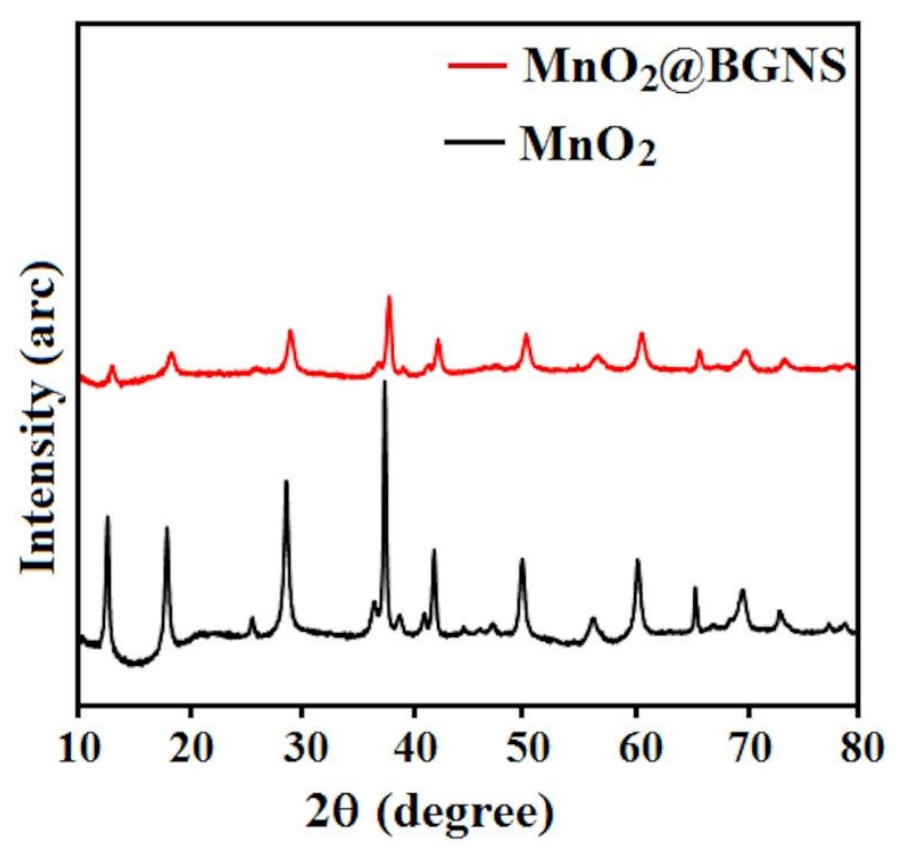

Fig. $1 \mathrm{XRD}$ of pure $\mathrm{MnO}_{2}$ nanotube and $\mathrm{MnO}_{2} @ \mathrm{BGNS}$ composite.

Raman spectroscopy was also performed to investigate the quality of the carbon materials and structural characteristic (disorder, defects and layers of carbon atoms) of the $\mathrm{MnO}_{2} @ \mathrm{BGNS}$ hybrid. For comparison, Fig. 2 shows the Raman spectra of pure GO and $\mathrm{MnO}_{2} @$ BGNS hybrid. As shown in Fig. 2, the Raman spectrum of GO shows two high intensity peaks at 1359 and $1588 \mathrm{~cm}^{-1}$ corresponding to the $\mathrm{D}$ and $\mathrm{G}$ bands, respectively ${ }^{22}$, and a wide $2 \mathrm{D}$ peak at $2688 \mathrm{~cm}^{-1}$. The $\mathrm{G}$ band arises from the in-plane bond stretch of the C-C sp ${ }^{2}$ bond, while the D band arises from the various types of defects such as $\mathrm{sp}^{3}$ defects, and the $2 \mathrm{D}$ band is due to the two-phonon double-resonant process $^{23}$. These defects are attributed to the oxidation and hydrogenation of carbon atoms during the synthesis of GO. 


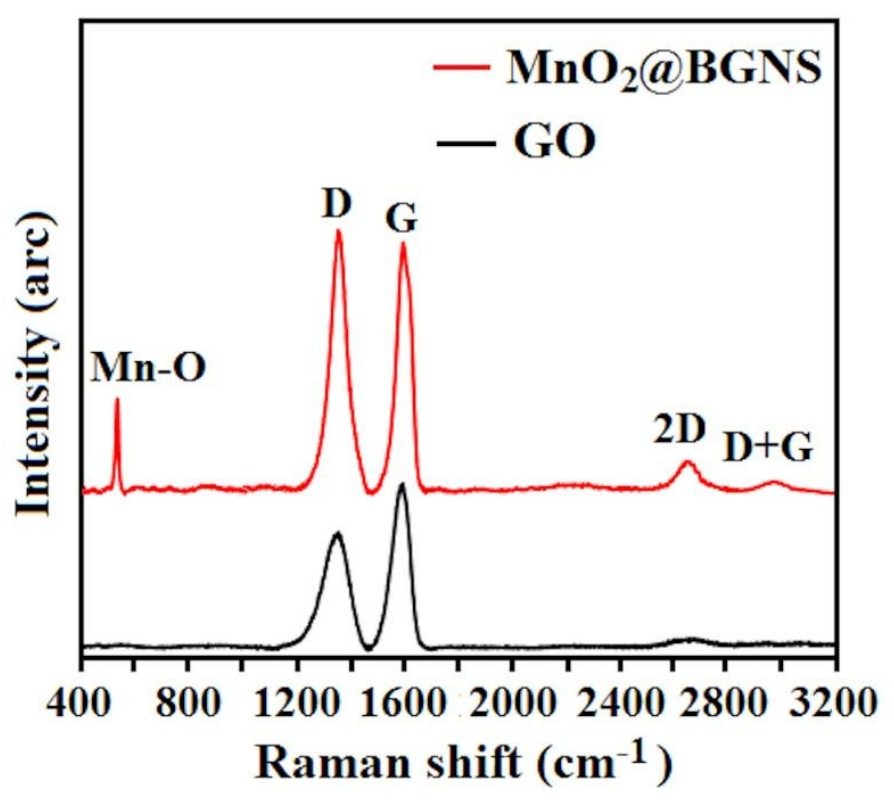

View Article Online DOI: 10.1039/C9SE00775J

Fig. 2 Raman spectra of GO and $\mathrm{MnO}_{2} @ \mathrm{BGNS}$ hybrid.

The presence of high intensity $\mathrm{D}$ and $\mathrm{G}$ bands in the $\mathrm{MnO}_{2} @ \mathrm{BGNS}$ lattice, clearly confirm the presence of many defects in the BGNS structure, which could be due to boron doping in the carbon lattice during the annealing process ${ }^{24}$. Moreover, the intensity ratio of the $\mathrm{I}_{\mathrm{D}} / \mathrm{I}_{\mathrm{G}}$ peak (1.23) of $\mathrm{MnO}_{2} @ \mathrm{BGNS}$ increases strongly compared to GO (0.88), which clearly suggests that the BGNS possesses higher defect density compared to GO, due to the boron doping during thermal annealing ${ }^{25}$. Furthermore, the increase in the intensity of the 2D band of $\mathrm{MnO}_{2} @ \mathrm{BGNS}$ hybrid compared to GO clearly shows an increase in the BGNS layer after thermal annealing. In addition to the D, G and 2D peaks, $\mathrm{MnO}_{2} @$ BGNS hybrid shows an extra weak D+G peak at 2941 $\mathrm{cm}^{-1}$, indicating that the thermal annealing process produces few-layers of BGNS ${ }^{24}$. Furthermore, special peak centred at $575 \mathrm{~cm}^{-1}$ is identified in the case of composite, which could be assigned to the Mn-O lattice vibration in $\mathrm{MnO}_{2}{ }^{26}$. The existence of MnO peak in Raman spectra of $\mathrm{MnO}_{2} @ \mathrm{BGNS}$ hybrid clearly indicates that $\mathrm{MnO}_{2}$ has been covalently anchored onto the surface of BGNS. 


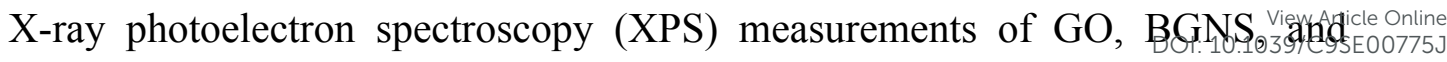
$\mathrm{MnO}_{2} @ \mathrm{BGNS}$ was performed to gain further insight into the chemical composition and boron content in BGNS (Fig. 3). Compared to the XPS spectrum of GO, the full range XPS spectra of the BGNS sample clearly reveals the presence of oxygen $(\mathrm{O}$ 1s peak at $531.5 \mathrm{eV})$ and carbon $(\mathrm{C} 1 \mathrm{~s}$ peak at $284.3 \mathrm{eV})$ atoms, as well as the presence of extra boron peaks (B 1s peak at $190.6 \mathrm{eV}$ ) with a $\mathrm{B}: \mathrm{C}$ atomic ratio of 0.18 , confirming that the boron atoms resulting from boric acid have been successfully doped into the GNS lattice ${ }^{27}$. Moreover, compared to the $\mathrm{C}: \mathrm{O}$ atomic ratio of $\mathrm{GO}(0.69)$, the $\mathrm{C}: \mathrm{O}$ atomic percentage of BGNS (2.65) significantly increases, which confirms the successful reduction of GO after thermal annealing (Fig. 3a).

Based on the Shirley algorithms, the high-resolution C 1s spectra of GO can be deconvoluted into three different peaks (Fig.3b). The high intensity peak centered at $286.9 \mathrm{eV}$ is attributed to the $\mathrm{C}-\mathrm{O}$ hydroxyl group, while the highest peak at $284.6 \mathrm{eV}$ is assigned to the $\mathrm{C}-\mathrm{C}$ epoxide group. The third wide peak at $288.8 \mathrm{eV}$ is assigned to the $\mathrm{O}-\mathrm{C}=\mathrm{O}$ of $\mathrm{GO}$. Compared to the $\mathrm{C} 1 \mathrm{~s}$ spectra of $\mathrm{GO}$, the $\mathrm{C} 1 \mathrm{~s}$ spectrum of BGNS contains the same type of $\mathrm{C}-\mathrm{O}, \mathrm{C}-\mathrm{C}$ and $\mathrm{O}-\mathrm{C}=\mathrm{O}$ groups but shifts to lower binding energy of $286.4 \mathrm{eV}, 284.5 \mathrm{eV}$, and $287.5 \mathrm{eV}$, respectively. It is noted that the peak around $281 \mathrm{eV}$ corresponds to the B-C group but is not observed in the $\mathrm{C}$ 1s spectrum of BGNS due to the low content boron atoms in the GNS lattice ${ }^{28}$. However, the C 1s binding intensity of BGNS decreases significantly compared to the GO. This is due the formation of $\mathrm{B}-\mathrm{C}$ bonding which causes the redistribution of the $\pi$-electron density and decrease the Fermi level of BGNS structure during thermal annealing ${ }^{28}$. 

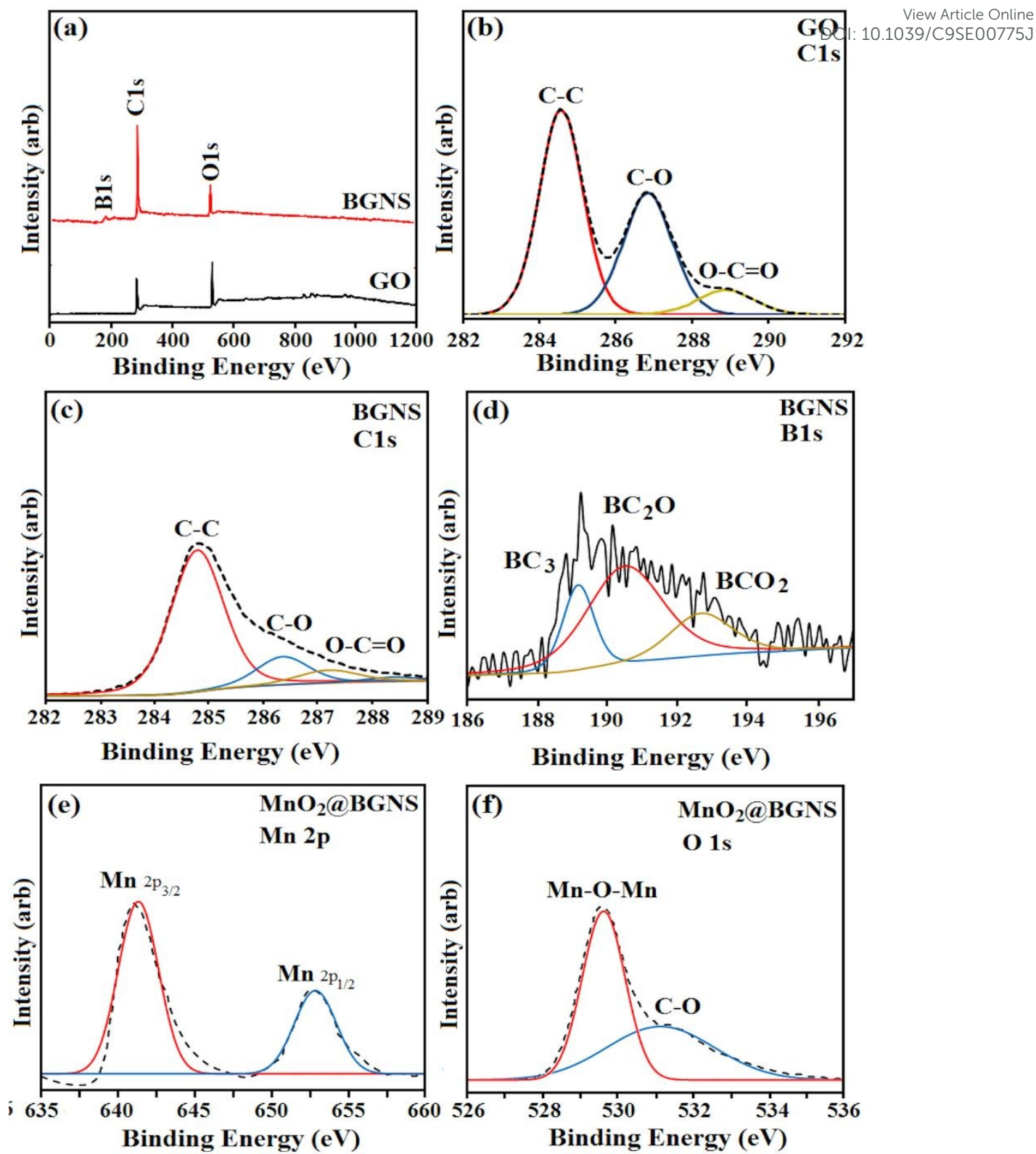

Fig. 3 (a) Wide scan XPS spectra of GO and BGNS. The high-resolution XPS spectra of (b) $\mathrm{C} 1 \mathrm{~s}$ of GO (c) C1s of BGNS, (d) B1s of BGNS, (e) Mn 2p of $\mathrm{MnO}_{2} @ \mathrm{BGNS}$, and (f) $\mathrm{O} 1 \mathrm{~s}$ of $\mathrm{MnO}_{2} @ \mathrm{BGNS}$ hybrid.

Details about the boron functional groups could be obtained by the deconvolution of the B 1s peak in the BGNS XPS spectrum (Fig. 3d). The B 1s peak of BGNS was deconvoluted into three different peaks. The peak at $188.8 \mathrm{eV}$ is attributed to the $\mathrm{BC}_{3}$ structure which results from the substitution of carbon atoms by boron atoms in the GNS lattice. The two different peaks at 190.3 and $192.2 \mathrm{eV}$ were attributed to the 
different types of boron groups. The first type is assigned to the $\mathrm{BC}_{2} \mathrm{O}$ structure IfH corresponds to the bonding of boron atoms with carbon and oxygen atoms. Finally, the peak at $192.2 \mathrm{eV}$ is attributed to the $\mathrm{BCO}_{2}$ structure which is formed by the bonding between the boron atoms with carbon and two oxygen atoms ${ }^{29}$. The XPS analysis clearly confirms the formation of the B-C groups in the GNS structure during thermal annealing. Furthermore, the high resolution $\mathrm{Mn} 2 \mathrm{p}$ spectrum of $\mathrm{MnO}_{2} @ \mathrm{BGNS}$ hybrid (Fig. 3e) clearly shows that the peaks centred at 641.8 and $653.2 \mathrm{eV}$ could be attributed to $\mathrm{Mn} 2 \mathrm{p}_{3 / 2}$ and $\mathrm{Mn} 2 \mathrm{p}_{1 / 2}$, respectively, confirming the formation of $\mathrm{MnO}_{2}$ in the $\mathrm{MnO}_{2} @ \mathrm{BGNS}$ hybrid ${ }^{30}$ In the case of oxygen, the deconvolution peaks of $\mathrm{O} 1 \mathrm{~s}$ spectrum of $\mathrm{MnO}_{2} @ \mathrm{BGNS}$ hybrid (Fig. 3f) could be divided into two different sharp and broad peaks centred at 529.7 and $531.2 \mathrm{eV}$, which are attributed to Mn-O-Mn and C-O bonding configuration in $\mathrm{MnO}_{2} @ \mathrm{BGNS}$ hybrid, respectively ${ }^{30}$.

TEM analysis was performed to study the morphology and structure of the assynthesized pure $\mathrm{MnO}_{2}$ nanotubes, pure BGNS and $\mathrm{MnO}_{2} @$ BGNS composite (Figs. 4 and 5). The low magnification TEM image of the as-synthesized $\mathrm{MnO}_{2}$ shows nanotube shape of uniform surface structures (Fig. 4a). In addition, a more careful and close-up view reveals that the $\mathrm{MnO}_{2}$ nanotubes are uniform with an average length shorter than $3 \mu \mathrm{m}$ (Fig. 4b). The HRTEM image of pure $\mathrm{MnO}_{2}$ nanotubes after $12 \mathrm{~h}$ hydrothermal process is shown in the inset of Fig. $4 \mathrm{~b}$. As seen, the crystallinity of the $\mathrm{MnO}_{2}$ nanotube is rather high and the lattice fringe of $0.50 \mathrm{~nm}$ corresponds to the (200) crystal planes of tetragonal $\mathrm{MnO}_{2}$ as confirmed by the HRTEM analysis. The TEM image of pure BGNS reveals a crumpled sheet-like layered structure of several micrometers in diameter (Fig. 5a). The crumpling could be due to the defects in the structure during the thermal annealing. A low-magnification TEM image of $\mathrm{MnO}_{2} @ \mathrm{BGNS}$ composite clearly shows that the $\mathrm{MnO}_{2}$ nanotubes are uniformly and densely distributed on the 


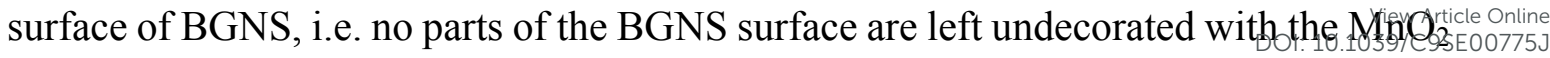
nanotubes which suggest that the BGNS can act as a conductive platform connecting the $\mathrm{MnO}_{2}$ nanotubes (Fig. 5b). This facilitates the transfer of charged carriers between the conductive platform and the catalyst, which enhances the electrocatalytic performance of ORR. 


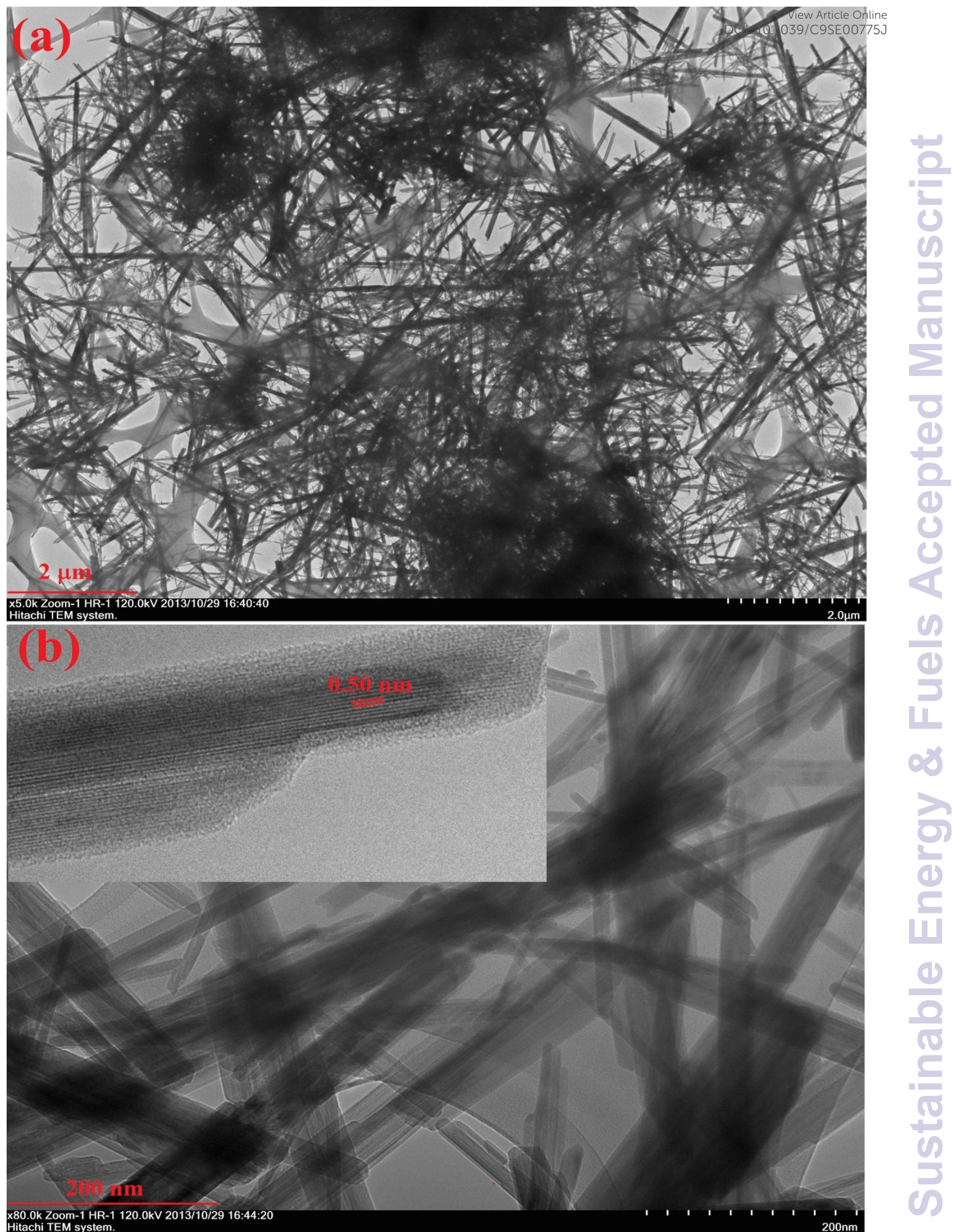

Fig. $4(a, b)$ Low and high magnification TEM images of $\mathrm{MnO}_{2}$ nanotubes. Inset: HR-TEM image of $\mathrm{MnO}_{2}$ nanotube. 


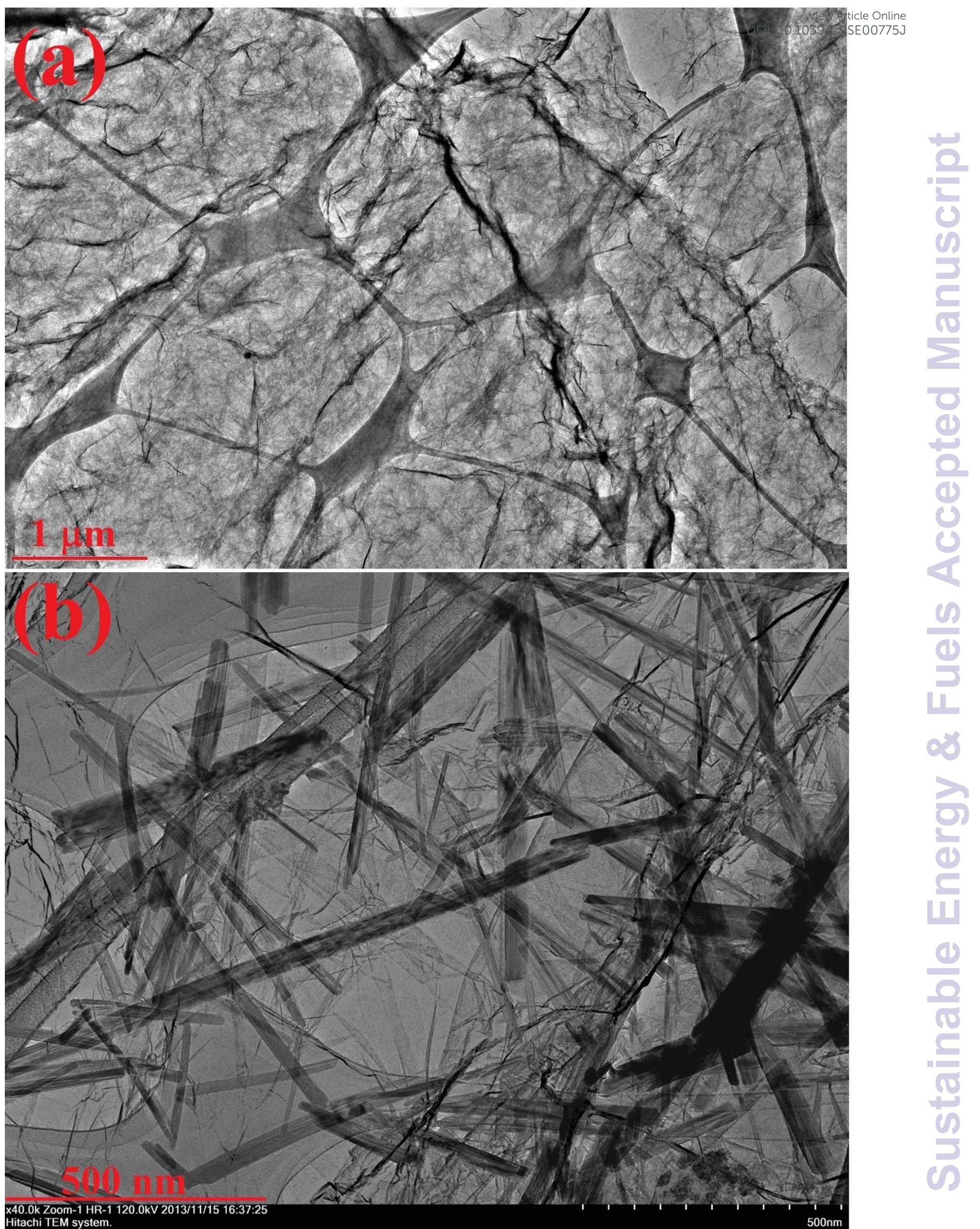

Fig. 5 (a) TEM image of pure BGNS, (b) TEM image of $\mathrm{MnO}_{2} @ B$ BNS composite. 
3.2. Electrocatalytic activity for oxygen reduction

To gain insight on the electrocatalytic activity of the $\mathrm{MnO}_{2} @ \mathrm{BGNS}$-modified GCE electrode, the kinetics of ORR reaction and investigation of the number of transferred electrons (n), linear sweep voltammetry (LSV) was performed on a rotating disc electrode (RDE) at $2000 \mathrm{rpm}$ in $\mathrm{O}_{2}$ saturated $0.1 \mathrm{M} \mathrm{KOH}$ solution at $20 \mathrm{mV} \mathrm{s}^{-1}$.
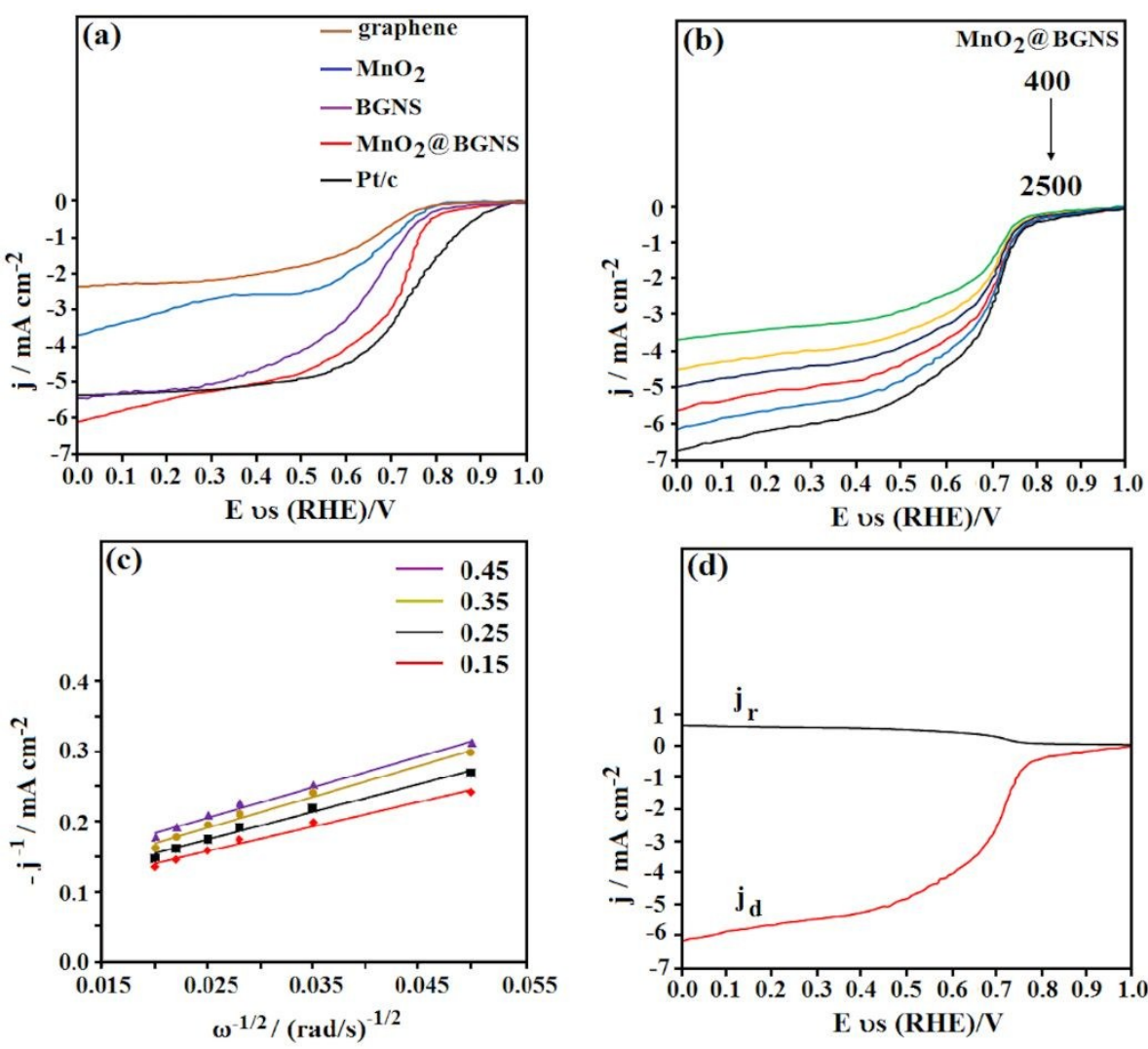

Fig. 6 (a) Linear sweep voltammetry curves (LSVs) of ORR on different electrodes in an $\mathrm{O}_{2}$-saturated 0.1 M KOH aqueous solution (rotation rate: $2000 \mathrm{rpm}$ ), (b) LSVs of ORR on $\mathrm{MnO}_{2} @$ BGNS-modified GCE at different rotation rates (400, 800, 1200, 1600, 2000, and $2500 \mathrm{rpm}$ ) in an $\mathrm{O}_{2}$-saturated $0.1 \mathrm{M} \mathrm{KOH}$ solution, (c) The $\mathrm{K}-\mathrm{L}$ plots for ORR on $\mathrm{MnO}_{2} @$ BGNS-modified GCE at different electrode potentials, (d) RRDE test of ORR on $\mathrm{MnO}_{2} @ \mathrm{BGNS}$ in an $\mathrm{O}_{2}$-saturated $0.1 \mathrm{M} \mathrm{KOH}$ aqueous solution (rotation rate: $2000 \mathrm{rpm}$ ).

Fig. 6a shows the LSV curves of pure GNS, pure $\mathrm{MnO}_{2}$ nanotube, pure BGNS, $\mathrm{MnO}_{2} @ \mathrm{BGNS}$ hybrid and commercial grade 20 wt. \% platinum $(\mathrm{Pt} / \mathrm{C})$ catalyst at 2000 rpm. As seen, the voltammograms show two different regions i.e. the region between 0.5 to $1.0 \mathrm{~V}$ is assigned to the mixed kinetic diffusion control region while the region 


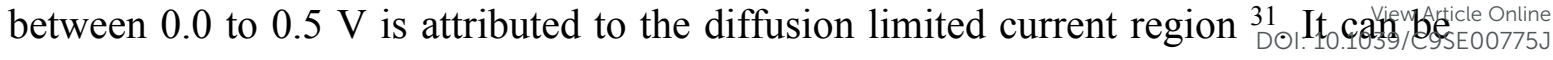
clearly observed that the $\mathrm{MnO}_{2} @$ BGNS hybrid and $\mathrm{Pt} / \mathrm{C}$ showed a prominent positive onset potential of 0.96 and $0.98 \mathrm{~V}$ at a current density of $-100 \mu \mathrm{A} \mathrm{cm}^{-2}$ compared with $0.91,0.93$, and $0.95 \mathrm{~V}$ for pure GNS, pure $\mathrm{MnO}_{2}$, and pure BGNS, respectively. Notably, the onset potential of GNS increased by the substitution of boron in GNS lattice, which reveals that boron substitution increased catalytic activity of GNS due to stronger B-O bonding compared with C-O bonding (See DFT discussion). The half wave potential (the potential where the current is half of the limiting current) is another important parameter in the ORR activity. As seen in Fig. 6a, the half wave potential of $\mathrm{MnO}_{2}$ nanotube exhibits a more positive potential in the presence of BGNS in the $\mathrm{MnO}_{2} @ \mathrm{BGNS}$ hybrid electrode. Moreover, the $\mathrm{MnO}_{2} @ \mathrm{BGNS}$ electrode showed higher diffusion limiting current density of $-6.1 \mathrm{~mA} \mathrm{~cm}^{-2}$, which is considerably higher compared to the pure rGO $\left(-2.36 \mathrm{~mA} \mathrm{~cm}^{-2}\right)$, pure $\mathrm{MnO}_{2}\left(-3.70 \mathrm{~mA} \mathrm{~cm}{ }^{-2}\right)$, pure BGNS (-5.43 $\left.\mathrm{mA} \mathrm{cm}^{-2}\right)$, and $\mathrm{Pt} / \mathrm{C}\left(-5.42 \mathrm{~mA} \mathrm{~cm}^{-2}\right)$ electrodes, respectively. Notably, the $\mathrm{MnO}_{2}$ nanotube electrode showed a two-step process for the ORR, which is accompanied by the formation of an intermediate peroxide anion $\left(\mathrm{HO}_{2}{ }^{-}\right)^{32}$. In contrast, the $\mathrm{MnO}_{2} @ \mathrm{BGNS}$ hybrid as a potential substitute for $\mathrm{Pt} / \mathrm{C}$, as it shows a four-electron pathway, which is more efficient and favorable for the ORR. This result demonstrates that the $\mathrm{MnO}_{2} @ \mathrm{BGNS}$, as in the case of $\mathrm{Pt} / \mathrm{C}$, possesses higher ORR electrocatalytic activity than the pure $\mathrm{MnO}_{2}$ due to faster reaction kinetics in addition to a higher number of transferred electrons.

The reaction kinetics of $\mathrm{MnO}_{2} @ B$ BGNS-modified GCE was estimated using ORR polarization method at varying rotation speeds as depicted in Fig.6b. As seen, the reduction current density of the $\mathrm{MnO}_{2} @ \mathrm{BGNS}$-modified GCE increases with the rotation rate from 400 to $2500 \mathrm{rpm}(400,800,1200,1600,2000$ and $2500 \mathrm{rpm})$. This 
is due to the decrease in the diffusion layer with the increase of the rotation ratiens3ticle Online The kinetic-limiting current density and the number of electron transferred per oxygen molecule in ORR at the $\mathrm{MnO}_{2} @$ BGNS-modified GCE was calculated by the Koutecky-Levich (K-L) plots at different potentials $(0.15,0.25,0.35$, and $0.45 \mathrm{~V})$. As seen in Fig. 6c, the $\mathrm{K}-\mathrm{L}$ plots at different potentials are almost parallel with each other with good linearity, which indicates a first-order reaction kinetics with respect to the concentration of dissolved $\mathrm{O}_{2}$. The number of electron transferred at the $\mathrm{MnO}_{2} @ \mathrm{BGNS}$ hybrid nanocomposite was calculated by the $\mathrm{K}-\mathrm{L}$ equation ${ }^{34}$ inside the potential ranges of 0.15 to $0.70 \mathrm{~V}$ :

$\frac{1}{j}=\frac{1}{j_{k}}+\frac{1}{B \omega^{1 / 2}}$

$$
\begin{aligned}
& B=0.2 n F\left(D_{O_{2}}\right)^{2 / 3} v^{-1 / 6} C_{O_{2}} \\
& j_{k}=n F K C_{O_{2}}
\end{aligned}
$$

where $\mathrm{j}$ is the measured current density from the ORR LSV curve, $\mathrm{j}_{\mathrm{k}}$ is the kinetic current density ( Based on the linear regression equation: 0.072, 0.074, 0.080, and 0.089 $\mathrm{mA} \mathrm{cm}{ }^{-2}$ for $0.15,0.25,0.35$, and $0.45 \mathrm{~V}$, respectively), $\omega$ is the RDE rotation rate $(\mathrm{rpm}), \mathrm{n}$ is the number of electrons transferred in the ORR, $\mathrm{F}$ is the Faraday constant ( $\mathrm{F}$ $\left.=96485 \mathrm{C} \mathrm{mol}^{-1}\right), D_{\mathrm{O}_{2}}$ is the diffusion coefficient of dissolved $\mathrm{O}_{2}$ in $\mathrm{KOH}$ solution $(1.9$ $\left.\times 10^{-5} \mathrm{~cm}^{2} \mathrm{~s}^{-1}\right), C_{O_{2}}$ is the concentration of dissolved $\mathrm{O}_{2}$ in the solution $\left(1.2 \times 10^{-3} \mathrm{~mol}\right.$ $\left.\mathrm{L}^{-1}\right), K$ is the electron transfer rate constant, and $v$ is the kinematic viscosity of the $\mathrm{KOH}$ solution $\left(0.01 \mathrm{~cm}^{2} \mathrm{~s}^{-1}\right)^{35}$. According to eqns. (1) and (2), the number of electrons transferred at the $\mathrm{MnO}_{2} @ \mathrm{BGNS}$-modified GCE is estimated as 3.75 over a potential range between 0.15 to $0.45 \mathrm{~V}$, which demonstrates that the ORR process at the $\mathrm{MnO}_{2} @ \mathrm{BGNS}$ hybrid electrode is a single-step process with four electron reduction pathway. Moreover, to get further information on the pathway of the oxygen reduction 


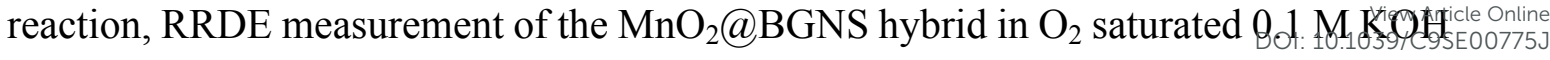
at $20 \mathrm{mV} \mathrm{s}^{-1}$ was also performed (Fig. 6d). The number of electrons transferred at the $\mathrm{MnO}_{2} @$ BGNS hybrid and $\mathrm{H}_{2} \mathrm{O}_{2}$ yield in ORR was calculated based on $\left(j_{r} / j_{d}\right) 35$ :

$$
\begin{aligned}
& n=4 \times \frac{\left|j_{d}\right|}{\left|j_{d}\right|+j_{r / N}} \\
& H_{2} O_{2} \%=200 \times \frac{j_{r / N}}{\left|j_{d}\right|+j_{r / N}}
\end{aligned}
$$

Where, $j_{r}$ is the ring current density representative of the $\mathrm{H}_{2} \mathrm{O}_{2}$ oxidation, $j_{d}$ is the disk current density representative of the ORR and $\mathrm{N}$ is the current collection efficiency at the RRDE. As seen in Fig. 6d, the disk current density is much higher than the ring current density. This indicates that the main product of the ORR at the $\mathrm{MnO}_{2} @$ BGNS hybrid nanocomposite was $\mathrm{H}_{2} \mathrm{O}$, compared to the yield of $\mathrm{H}_{2} \mathrm{O}_{2}$ which is below 9\%. Moreover, the number of electrons transferred is $\sim 3.7$, which is consistent with the K-L plots. To the best of our knowledge, all of these measurements indicate that the electrocatalytic activity of $\mathrm{MnO}_{2} @$ BGNS-modified GCE towards ORR is comparable with recently reported ORR electrocatalyst (Table 1).

Table 1. A Summary and a comparison of the present work with previous reports in the

\begin{tabular}{|c|c|c|c|c|c|}
\hline Modified electrode & Electrolyte & $\mathbf{V}_{\text {onset }}(\mathbf{V})$ & $\mathbf{n}$ & Retention & References \\
\hline CoFe carbide-NG & $0.1 \mathrm{M} \mathrm{KOH}$ & 0.96 & 3.6 & $96.2 \%$ after $12000 \mathrm{~s}$ & 36 \\
\hline $\mathrm{MnFe}_{2} \mathrm{O}_{4} / \mathrm{NiCo}_{2} \mathrm{O}_{4}$ & $0.1 \mathrm{M} \mathrm{KOH}$ & 0.88 & 4 & ------------ & 37 \\
\hline CoS-carbon cloth & $0.1 \mathrm{M} \mathrm{KOH}$ & 0.85 & 3.7 & $99 \%$ after $40000 \mathrm{~s}$ & 38 \\
\hline Carbon film & $0.1 \mathrm{M} \mathrm{KOH}$ & 0.59 & 2.6 & $63.1 \%$ after $35000 \mathrm{~s}$ & 39 \\
\hline $\mathrm{Mn}_{2} \mathrm{O}_{3} / \mathrm{TOPO} / \mathrm{rGO}$ & $0.1 \mathrm{M} \mathrm{KOH}$ & 0.91 & 3.9 & $90 \%$ after 10000 & 33 \\
\hline B-graphene & $0.1 \mathrm{M} \mathrm{KOH}$ & 0.95 & 3.5 & $75 \%$ after 12000 & 28 \\
\hline $\mathrm{Pt}-\mathrm{N}-\mathrm{MoSe}_{2}-\mathrm{BC}$ & $0.5 \mathrm{M} \mathrm{H}_{2} \mathrm{SO}_{4}$ & 0.63 & 4 & $88.1 \%$ after $3500 \mathrm{~s}$ & 40 \\
\hline $\mathrm{NG} / \mathrm{VC}$ & $1 \mathrm{MKOH}$ & 0.85 & 3.8 & -1 & 41 \\
\hline $\mathrm{MnO}_{2} @ \mathrm{BGNS}$ & $0.1 \mathrm{M} \mathrm{KOH}$ & 0.96 & 3.75 & $88 \%$ after $12000 \mathrm{~s}$ & This work \\
\hline
\end{tabular}
literature. 


\subsection{Selectivity and durability}

The selectivity and long-term durability are two important parameters for evaluating the electrocatalytic activity of ORR at the $\mathrm{MnO}_{2} @ \mathrm{BGNS}$-modified GCE. The chronoamperometric (current vs. time) response of the RDE at the $\mathrm{MnO}_{2} @ \mathrm{BGNS}$ hybrid and $\mathrm{Pt} / \mathrm{C}$ electrocatalyst in $0.1 \mathrm{M} \mathrm{KOH}$ solution at $2000 \mathrm{rpm}$ in the absence and presence of 1M methanol was investigated (Fig. 7a).
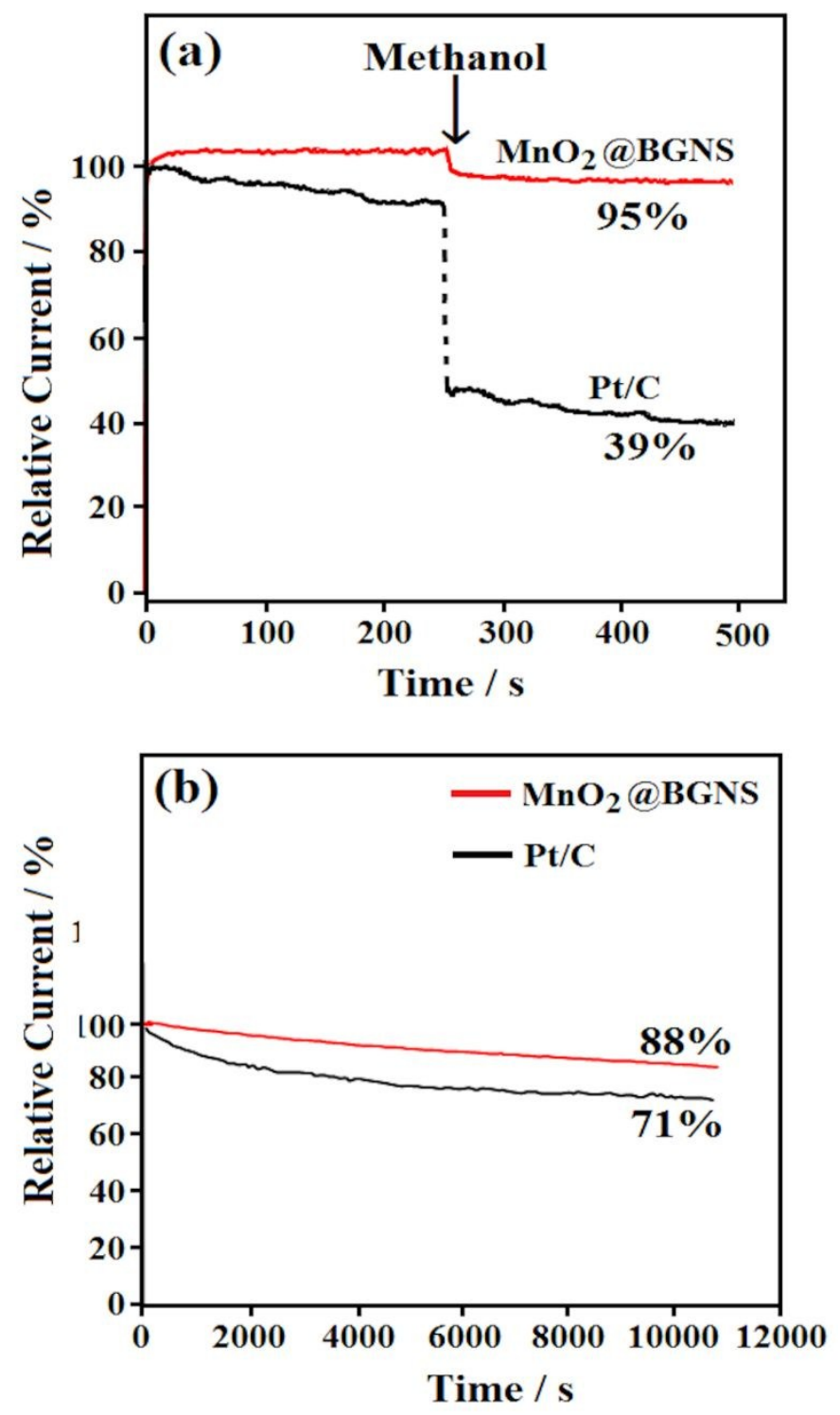

Fig. 7 (a) The methanol crossover effect and (b) durability test of $\mathrm{MnO}_{2} @ \mathrm{BGNS}$ and Pt/C in an $\mathrm{O}_{2}$-saturated $0.1 \mathrm{M} \mathrm{KOH}$ aqueous solution (rotation rate: $2000 \mathrm{rpm}$ ). 


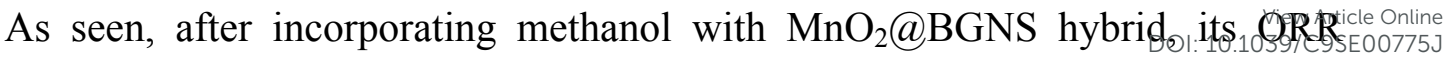
current slightly reduced (almost 5\%). In contrast, the current density of $\mathrm{Pt} / \mathrm{C}$ cathode decreases significantly in the presence of $1 \mathrm{M}$ methanol, which is attributed to the presence of methanol oxidation on the surface of the $\mathrm{Pt} / \mathrm{C}$ catalyst. Therefore, the $\mathrm{MnO}_{2} @ \mathrm{BGNS}$ hybrid possesses high selectivity towards the ORR even in the presence of methanol at high concentration. The electrode durability is another important factor in the ORR process. Therefore, the amperometric response of the $\mathrm{MnO}_{2} @ \mathrm{BGNS}$ hybrid was performed at $-0.5 \mathrm{~V}$ over a $3 \mathrm{~h}$ period (Fig. 7b). The $\mathrm{MnO}_{2} @ \mathrm{BGNS}$ hybrid remained stable throughout the experiment with only $12 \%$ decrease from the initial current density over $3 \mathrm{~h}$. In contrast, the Pt/C catalyst suffered a larger current decrease of $29 \%$ over the same time period. Therefore, the $\mathrm{MnO}_{2} @ \mathrm{BGNS}$-modified GCE exhibited good stability for the ORR process, in addition the electrocatalytic activity is comparable to the commercial $\mathrm{Pt} / \mathrm{C}$ electrocatalyst.

From the RDE, LSV curves and amperometric responses, the reason for the enhanced ORR activity of the $\mathrm{MnO}_{2}$ nanotubes in the presence of BGNS is attributed to the synergistic effect between the two components, which leads to an increased surface area of the hybrid nanocomposite in the presence of BGNS. From the BET results (Fig. 8a), the surface area and total pore volume of $\mathrm{MnO}_{2} @ \mathrm{BGNS}$ hybrid was $256.4 \mathrm{~m}^{2} \mathrm{~g}^{-1}$ and $0.92 \mathrm{~cm}^{3} \mathrm{~g}^{-1} \mathrm{~nm}^{-1}$, respectively, which is much larger than pure $\mathrm{MnO}_{2}$ with surface area and total pore volume of $62.1 \mathrm{~m}^{2} \mathrm{~g}^{-1}$ and $0.22 \mathrm{~cm}^{3} \mathrm{~g}^{-1} \mathrm{~nm}^{-1}$, respectively. Moreover, BET specific surface area measurement showed pore diameter of $5 \mathrm{~nm}$ for the $\mathrm{MnO}_{2} @ \mathrm{BGNS}$ hybrid, which is slightly larger than pure $\mathrm{MnO}_{2}$ (inset of Fig. 8a). Therefore, the presence of BGNS in the $\mathrm{MnO}_{2} @ \mathrm{BGNS}$ hybrid nanocomposite increases the total surface area, with an increase of porosity in the 


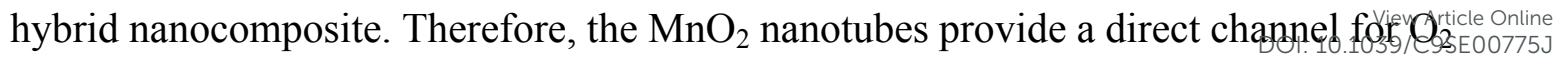
gas transport to the BGNS layer, which facilitates the ORR catalytic activity.
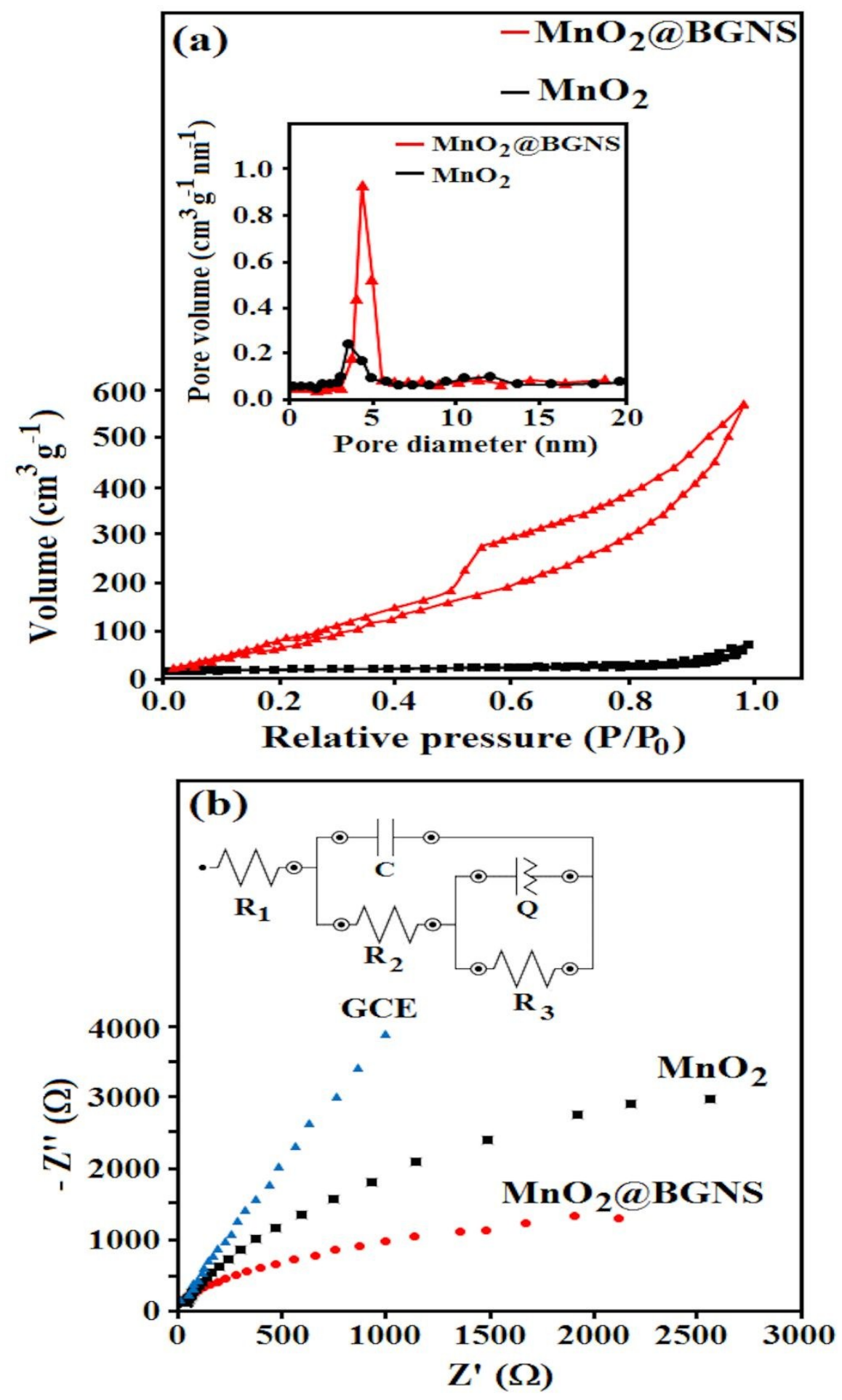

Fig. 8 (a) Nitrogen adsorption/desorption isotherms; inset: pore size distribution plots of $\mathrm{MnO}_{2}$ nanotubes and $\mathrm{MnO}_{2} @$ BGNS hybrid (b) Nyquist plots of GCE, $\mathrm{MnO}_{2}$, and $\mathrm{MnO}_{2} @$ BGNS-modified GCE electrode in $0.1 \mathrm{M} \mathrm{KCl}$ solution containing $1 \mathrm{mM}$ $\mathrm{Fe}(\mathrm{CN})_{6}^{3-/ 4-}(1: 1)$; inset: the equivalent circuit. 
The enhanced ORR catalytic activity at the $\mathrm{MnO}_{2} @ \mathrm{BGNS}$ hybrid nangcomplogshieticle Online compared to the pure $\mathrm{MnO}_{2}$ nanotubes could be attributed to the increase in electrical conductivity of the hybrid by the incorporation of BGNS. Therefore, to investigate the kinetics of the electrode reaction and ion diffusion process of the cathodes, electrochemical impedance spectroscopy (EIS) was conducted at a $5 \mathrm{mV}$ AC signal between $0.1-10^{5} \mathrm{~Hz}$ frequency ranges. The Nyquist plots of the bare GCE, $\mathrm{MnO}_{2}$ modified GCE and $\mathrm{MnO}_{2} @$ BGNS-modified GCE in $1 \mathrm{mM} \mathrm{Fe}(\mathrm{CN})_{6}{ }^{3-/ 4-}(1: 1)$ in 0.1 $\mathrm{M} \mathrm{KCl}$ supporting electrolyte are shown in Fig. $8 \mathrm{~b}$. To further analyze the behavior of electrodes, the Nyquist plots of the electrodes were fitted by a complex equivalent circuit, as shown in the inset of Fig. 8b. In the fitting circuit, $R_{1}, R_{2}, Q$, and $C$ are the solution resistance, charge transfer resistance, constant phase element, and the double layer capacitance, respectively ${ }^{42}$. The Faradaic charge transfer process over the interface of electrode-electrolyte resulted in a semicircle diameter at low frequency region, in which its diameter represents the electron transfer resistance from the solution to the coating layer $\left(\mathrm{R}_{2}\right)$. The charge transfer resistance value was obtained from the intersection point of the semicircle diameter at low frequency regions. The $\mathrm{Q}$ and $\mathrm{R}_{3}$ was introduced in the fitting procedure to obtain a good agreement between the simulated and experimental data. The Nyquist plot of bare GCE shows a straight line, which suggests that the $\mathrm{R}_{2}$ is almost negligible. As can be seen in Table 2, the solution resistances of $\mathrm{MnO}_{2}$ and the $\mathrm{MnO}_{2} @$ BGNS-modified GCE hybrid were almost the same $\left(\mathrm{R}_{1}\right)$. However, the $\mathrm{R}_{2}$ of $\mathrm{MnO}_{2} @ \mathrm{BGNS}$-modified GCE is smaller than the $\mathrm{MnO}_{2}-$ modified GCE (Table 2), which indicates that the presence of BGNS increases the electrical conductivity of the hybrid electrode. Therefore, the enhanced ORR catalytic activity of the hybrid electrodes is due to the increased conductivity, which clearly improves the ORR electrocatalytic activity of the electrode for a faster rate of interfacial 


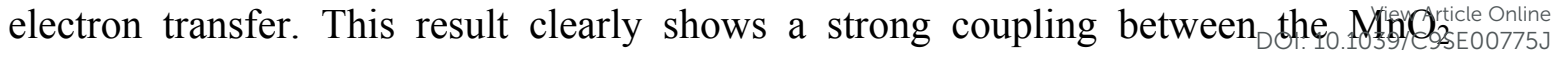
nanotubes and BGNS which improves the rate of charge transfer and enhances the adsorption of $\mathrm{O}_{2}$ molecules, for a higher ORR electrocatalytic activity at the $\mathrm{MnO}_{2} @ \mathrm{BGNS}$ hybrid nanocomposite.

Table 2. Electrochemical parameters obtained from the simulation of the EIS results.

\begin{tabular}{lcccccc}
\hline Modified electrode & $\begin{array}{c}\mathbf{R}_{\mathbf{1}} \\
\left(\Omega . \mathrm{cm}^{2}\right)\end{array}$ & $\begin{array}{c}\mathbf{R}_{\mathbf{2}} \\
\left(\Omega . \mathrm{cm}^{2}\right)\end{array}$ & $\begin{array}{c}\mathbf{R}_{\mathbf{3}} \\
\left(\Omega . \mathrm{cm}^{2}\right)\end{array}$ & $\begin{array}{c}\mathbf{C} \\
\left(\mu \mathrm{F} . \mathrm{cm}^{2}\right)\end{array}$ & $\begin{array}{c}\mathbf{Q} \\
\mathrm{Y}_{0}\left(\mu \Omega^{-1} \cdot \mathrm{s}^{\mathrm{n}} \mathrm{cm}^{-2}\right)\end{array}$ & $\mathbf{n}$ \\
\hline $\mathrm{MnO}_{2}$-GCE & 8.2 & 25.4 & $3.5 \times 10^{6}$ & 8.5 & 10.1 & 0.91 \\
$\mathrm{MnO}_{2} @ \mathrm{BGNS-GCE}$ & 9.1 & 3.8 & $312 \times 10^{3}$ & 4.6 & 5.2 & 0.88
\end{tabular}

\subsection{Electronic properties of $\mathrm{MnO}_{2} @$ BGNS.}

DFT simulations were performed to investigate the role of Boron in the $\mathrm{MnO}_{2} @ \mathrm{BGNS}$. The crystal structure of GNS, BGNS, $\mathrm{MnO}_{2}$ unit and super cell, $\mathrm{MnO}_{2}$ (slab), $\mathrm{MnO}_{2} @$ GNS and $\mathrm{MnO}_{2} @ \mathrm{BGNS}$ are optimized as depicted in Fig 9. As discussed earlier, the $\mathrm{MnO}_{2} @ \mathrm{BGNS}$ heterojunction is superior compared to the pristine $\mathrm{MnO}_{2}$ and $\mathrm{MnO}_{2} @$ GNS. Furthermore, the mismatch of the $\mathrm{MnO}_{2} @ \mathrm{BGNS}$ heterojunction is almost negligible (see Fig. 9f). Moreover, the stability of the $\mathrm{MnO}_{2}$ can be confirmed from its positive surface formation energy. As a consequence of this stability, the $\mathrm{MnO}_{2}$ slab was selected to construct the $\mathrm{MnO}_{2} @$ GNS and $\mathrm{MnO}_{2} @ \mathrm{BGNS}$ heterostructures by placing a single layer of GNS and BGNS on the surface of $\mathrm{MnO}_{2}$, respectively. 


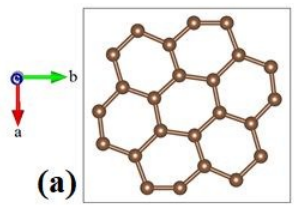

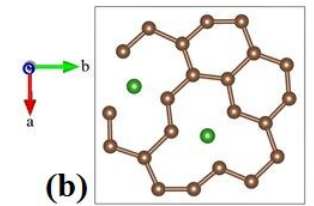

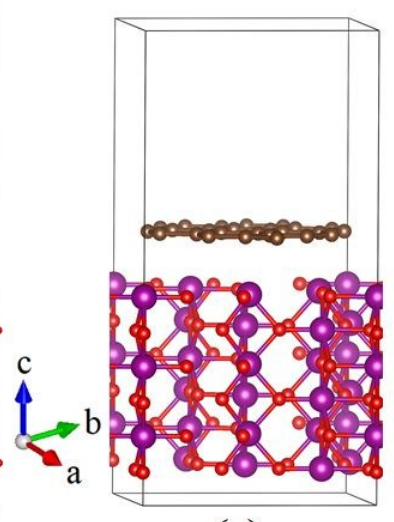

(e)

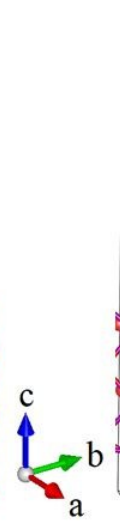

(d)

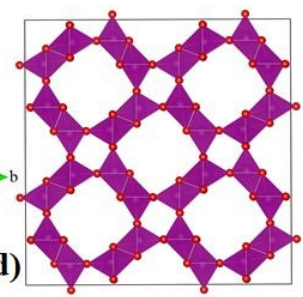

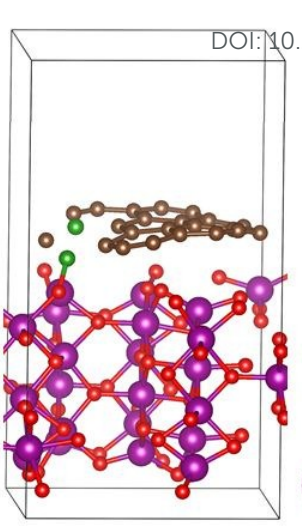

(f)

Fig. 9. Optimized structure of (a) GNS, (b) BGNS, (c) unit cell of $\mathrm{MnO}_{2}$, (d) 2x2x2 supercell of $\mathrm{MnO}_{2}$, (e) $\mathrm{MnO}_{2} @$ GNS and (f) $\mathrm{MnO}_{2} @ \mathrm{BGNS}$.

Both GNS and BGNS form strong interactions with the $\mathrm{MnO}_{2}$ surface. However, boron (BGNS) possesses a stronger bonding with the surface oxygen of $\mathrm{MnO}_{2}$. The adsorption energy of $\mathrm{MnO}_{2} @ \mathrm{BGNS}$ is higher compared to the $\mathrm{MnO}_{2} @ \mathrm{GNS}$. The nonbonding distance between $\mathrm{C}$ (GNS) and $\mathrm{O}\left(\mathrm{MnO}_{2}\right)$ is about $2.61 \AA$ while the B-O distance is $1.38 \AA$. Thus, the shorter bond distance (B-O) and higher adsorption energy of $\mathrm{MnO}_{2} @ \mathrm{~B}$-GNS suggest that the BGNS is completely attached on the $\mathrm{MnO}_{2}$ surface. Moreover, this effect results in the higher stability and efficient electrocatalytic activity of the $\mathrm{MnO}_{2} @ \mathrm{~B}-\mathrm{GNS}$. The partial density of states (PDOS) of $\mathrm{MnO}_{2} @$ GNS and $\mathrm{MnO}_{2} @$ BGNS was examined and shown in Fig. 11. As can be seen in Fig 10a, the orbitals of $\mathrm{C}$ and $\mathrm{O}$ are not fully hybridized which results a weaker interaction and lower charge transfer between two atoms (see Fig. 11). Furthermore, the bonding orbitals of $\mathrm{Mn}, \mathrm{O}$, and $\mathrm{C}$ are situated in the range of 0 to $-10 \mathrm{eV}$, along $\mathrm{X}$-axis. From Fig 11(a), we can see that the prominent bonding orbitals $(0$ to $-10 \mathrm{eV})$ are only the $\mathrm{O}$ atoms (red line), while that of $\mathrm{Mn}$ and $\mathrm{C}$ have low density of state. This is evidence of a not fully 


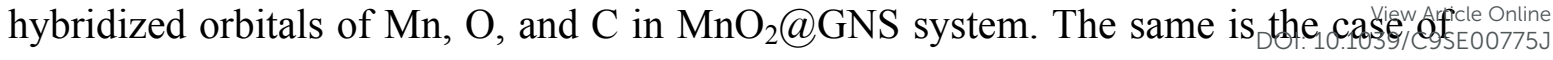
conduction band, where only Mn anti-bonding orbitals (0 to $10 \mathrm{eV})$ are prominent.
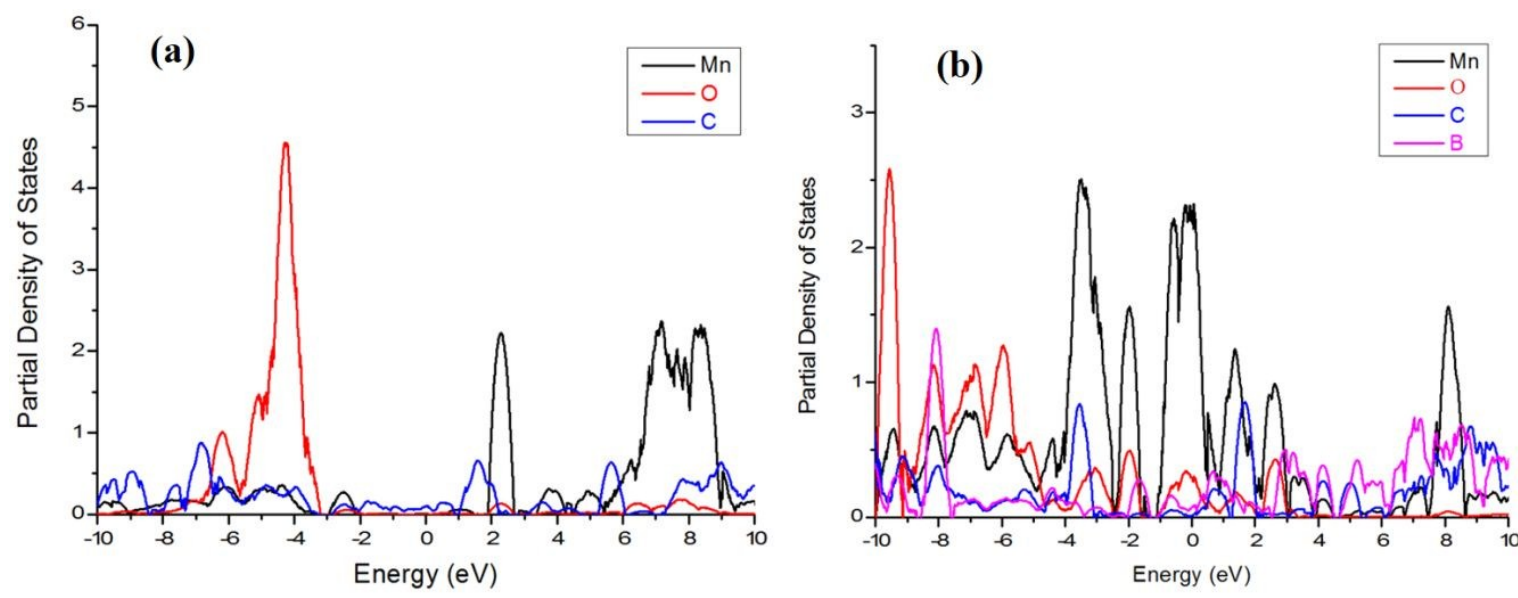

Fig. 10. PDOS of $\mathrm{Mn}, \mathrm{O}, \mathrm{C}$, and $\mathrm{B}$ in (a) $\mathrm{MnO}_{2} @$ GNS and (b) $\mathrm{MnO}_{2} @ \mathrm{BGNS}$.

On the other hand, both the bonding (valence band is shown in the range of 0 to $-10 \mathrm{eV}$ ) and anti-bonding orbitals (conduction band is shown in the range of 0 to $10 \mathrm{eV}$ ) of $\mathrm{Mn}, \mathrm{O}, \mathrm{C}$, and $\mathrm{B}$ in $\mathrm{MnO}_{2} @ \mathrm{BGNS}$, have a strong overlap with each other. All of these atoms have a similar density of state which results strong hybridization of these orbitals. And consequences stronger interaction and overall stability of $\mathrm{MnO}_{2} @ \mathrm{BGNS}$. The PDOS results are also consistent with the experimental measurements, both suggest that the B-O bond has a better capacity for electron transfer compared to the C-O. From the electronic structural analysis results, the B-O bonding is more active in the ORR compared to the $\mathrm{C}-\mathrm{O}$ due to stronger intermediate adsorption and better electron transfer capability of the B-O bond (Fig 11).

In order to clearly show the interface behavior of $\mathrm{MnO}_{2} @ \mathrm{GNS}$ or $\mathrm{MnO}_{2} @ \mathrm{BGNS}$, the area along c-direction (Z-direction) is very important. The electron localization function (ELF) of GNS, BGNS, $\mathrm{MnO}_{2}, \mathrm{MnO}_{2} @ \mathrm{GNS}$, and $\mathrm{MnO}_{2} @ \mathrm{BGNS}$, 
along z-direction is calculated which are shown in Figure 11. As can be analyzed 0 Figure $11(\mathrm{~d})$, the surface of $\mathrm{MnO}_{2}(0$ to $0.6 \AA$ ) interacts with GNS (0.7 to $0.9 \AA)$, followed by a vacuum ( 0.9 to $1 \AA$ ). The contours of ELF represents the charge density of the species. From Fig. 11, it can be seen that the BGNS shares its electronic charge density with the $\mathrm{MnO}_{2}$ compared to the $\mathrm{MnO}_{2} @$ GNS system. This type of charge distribution results a strong interaction between the $\mathrm{MnO}_{2}$ and $\mathrm{BGNS}$, which is analogous to the charge distribution of a typical $p-n$ junction semiconductor. The ELF strongly correlates with the results of PDOS, interaction energy, and experimental data.
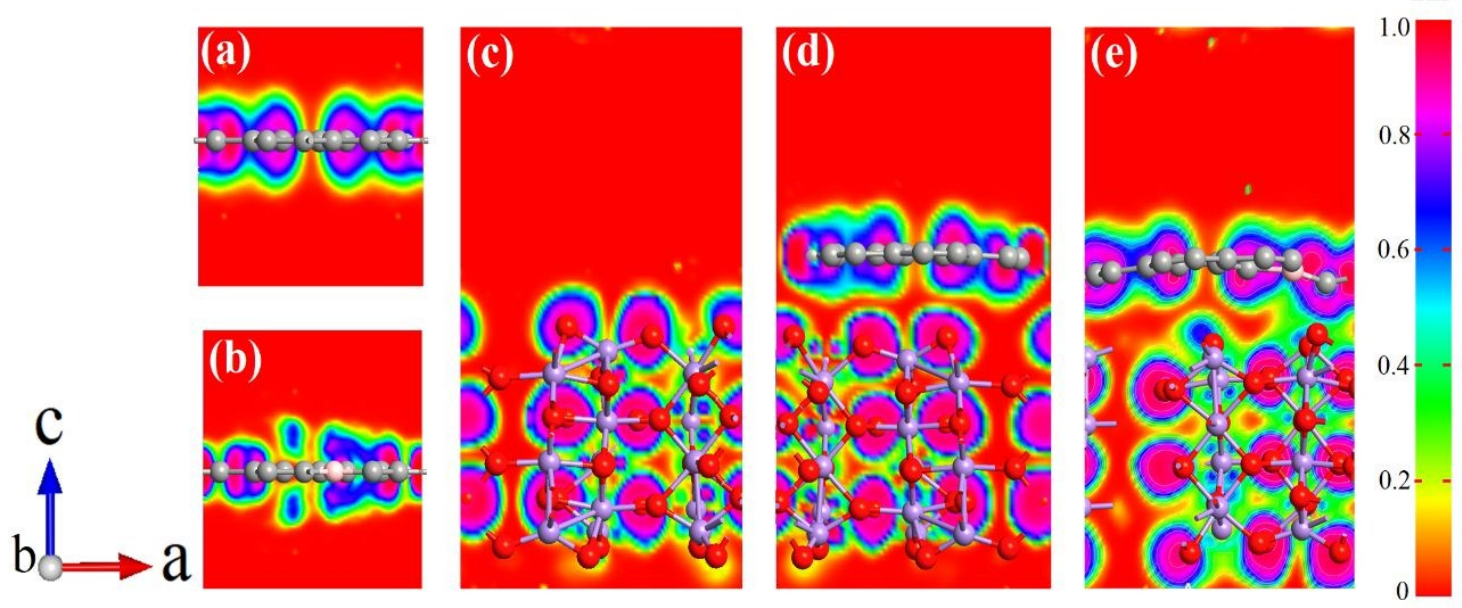

Fig. 11. Electronic localization functional maps of (a) GNS, (b) B-GNS, (c) $\mathrm{MnO}_{2}$, (d) $\mathrm{MnO}_{2} @$ GNS, and (e) $\mathrm{MnO}_{2} @ \mathrm{~B}-\mathrm{GNS}$.

Finally, the interaction of $\mathrm{MnO}_{2}$ with GNS or BGNS can be easily visualized from their electron density difference (EDD) plots, along the z-direction. As can be seen from Figure 12, the EDD value of $\mathrm{MnO}_{2}$ is in the range of 300 to $-300 \mathrm{eV} / \AA^{3}$ along $\mathrm{Y}$ axis. However, when it comes to the interface, then it drops down to 100 and -100 $\mathrm{eV} / \AA^{3}$. The charge redistribution at the interface of $\mathrm{MnO}_{2} @ \mathrm{BGNS}$ heterostructure confirms that BGNS donates the electronic cloud density to $\mathrm{MnO}_{2}$. The amount of charge density difference is around 0.072 electrons for $\mathrm{MnO}_{2} @ \mathrm{BGNS}$ heterostructure, calculated via Bader charge analysis. The charge accumulation and charge donation 
effect generate an electric field at the interface of $\mathrm{MnO}_{2} @ \mathrm{BGNS}$ heterostructure, Ith separates electrons and holes (vide supra). In Fig. 13, the green and yellow shaded areas represent the charge accumulation and depletion, respectively. Fig. 12 also demonstrates that the charge distribution phenomenon occurs at the interface of $\mathrm{MnO}_{2} @ \mathrm{BGNS}$, whereas no change was observed in pure $\mathrm{MnO}_{2}$ (see Fig. 12).

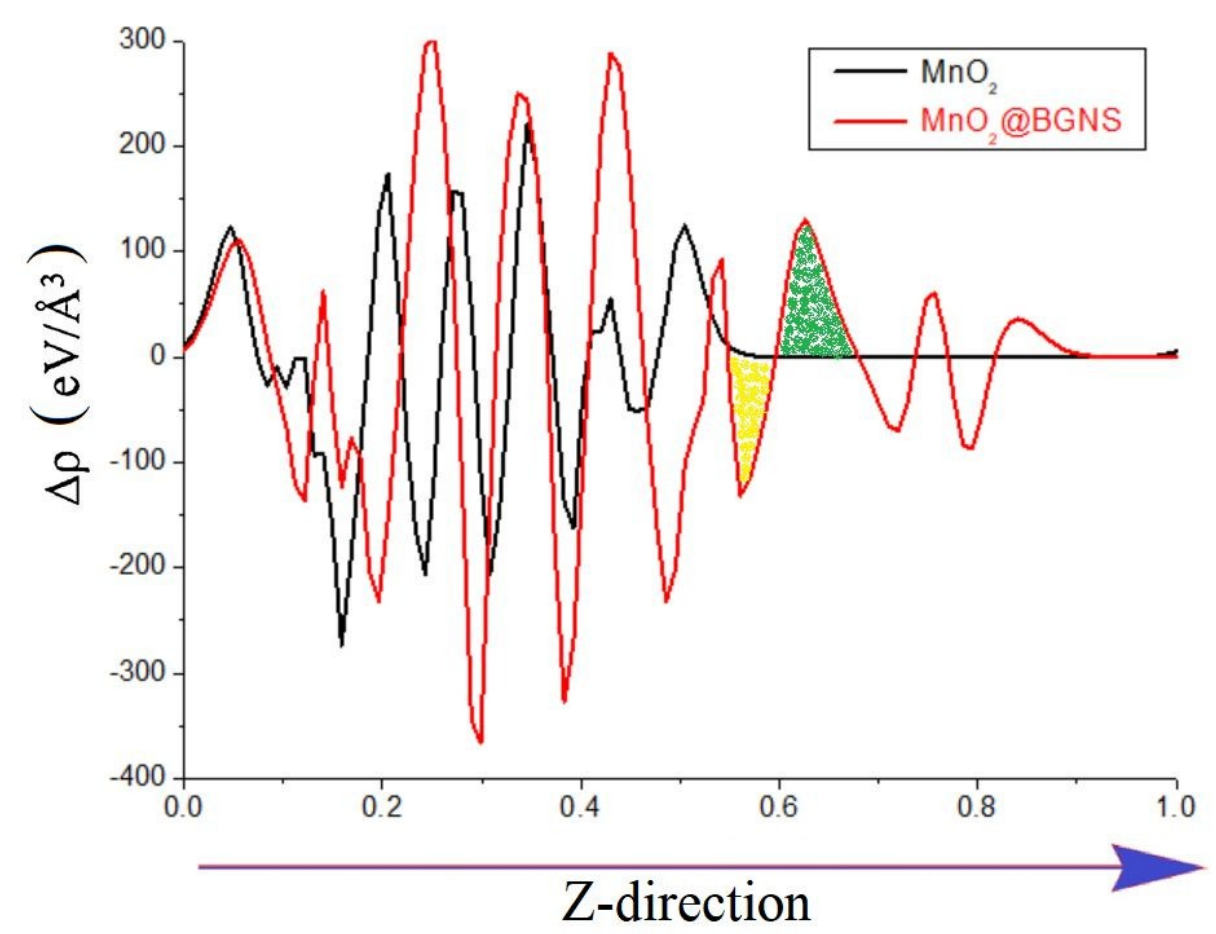

Fig. 12. Electron density difference $(\Delta \rho)$ along Z-direction for $\mathrm{MnO}_{2}$ and $\mathrm{MnO}_{2} @ \mathrm{BGNS}$. The green and yellow shaded areas represent the electron accumulation and donation, respectively.

\section{Conclusions}

In summary, BGNS were synthesized by thermal annealing of boric acid with $\mathrm{GO}$ at $700{ }^{\circ} \mathrm{C}$. In the second step, $\mathrm{MnO}_{2}$ nanotubes with an average particle size of 3 $\mu \mathrm{m}$ were loaded onto BGNS to prepare a $\mathrm{MnO}_{2} @ \mathrm{BGNS}$ hybrid nanocomposite as an 
electrocatalyst for the ORR. With regards to the onset potential, half wave potentialiavidicle Online electron transfer number, the $\mathrm{MnO}_{2} @ \mathrm{BGNS}$ hybrid nanocomposite exhibited excellent ORR electrocatalytic activity compared to the pure $\mathrm{MnO}_{2}$ nanotubes. Based on the EIS measurement and BET results, the enhanced ORR electrocatalytic activity of the hybrid electrode is attributed to the improved electrical conductivity and higher surface area of the hybrid nanocomposite due to the incorporation of $\mathrm{MnO}_{2}$ nanotubes on the surface of the BGNS. The $\mathrm{MnO}_{2} @$ BGNS-modified GCE showed advantages such as long term stability and excellent tolerance towards methanol. Finally, the experimental results are complemented with the density functional theory (DFT) calculations which shows strong correlations. It is found that the BGNS strongly interacts with the surface of $\mathrm{MnO}_{2}$ due to the strong electrostatic interaction and inter charge transfer process. The higher reactivity of the $\mathrm{MnO}_{2} @ \mathrm{BGNS}$ is confirmed with the presence of strong bonding of the B-O. Furthermore, the charge transfer and partial density of state analysis suggest that the electron transfer capability of the $\mathrm{B}-\mathrm{O}$ bonding is stronger compared to the pure GNS (where the $\mathrm{C}-\mathrm{O}$ bonding occur). Thus, it can be concluded that boron doping in GNS is an effective strategy for the design of an efficient ORR electrocatalyst.

\section{Acknowledgements}

This research is supported by RU Geran-Fakulti Program (GPF064B-2018), (GPF034B-2018), FRGS (FP071-2018A), PRGS (PR003-2018A) and University of Malaya Centre for Ionic Liquids (UMCiL). Finally, M.A.M.T. and H.U acknowledges financial support from Universiti Kebangsaan Malaysia through internal grant project No. DIP-2018-009. 


\section{References}

1 S. Sultan, J. N. Tiwari, J. Jang, A. M. Harzandi, F. Salehnia, S. J. Yoo and K. S. Kim, Adv. Energy Mater., 2018, 8, 1801002.

2 X. Wang, S.-I. Choi, L. T. Roling, M. Luo, C. Ma, L. Zhang, M. Chi, J. Liu, Z. Xie and J. A. Herron, Nat. Commun., 2015, 6, 7594.

3 M. Baumung, F. Schönewald, T. Erichsen, C. A. Volkert and M. Risch, Sustain. Energy Fuels, 2019, 3, 2218-2226.

4 J. B. Jasinski, D. Ziolkowska, M. Michalska, L. Lipinska, K. P. Korona and M. Kaminska, RSC Adv., 2013, 3, 22857-22862.

5 D. J. Davis, T. N. Lambert, J. A. Vigil, M. A. Rodriguez, M. T. Brumbach, E. N. Coker and S. J. Limmer, J. Phys. Chem. C, 2014, 118, 17342-17350.

6 C. Shi, G. L. Zang, Z. Zhang, G. P. Sheng, Y. X. Huang, G. X. Zhao, X. K. Wang and H. Q. Yu, Electrochim. Acta, 2014, 132, 239-243.

7 Z. Awan, Z. K. Ghouri and S. Hashmi, Int. J. Hydrogen Energy, 2018, 43, 2930-2942.

8 L. X. Zuo, L. P. Jiang, E. S. Abdel-Halim and J. J. Zhu, Ultrason. Sonochem., 2017, 35, 219-225.

9 G. Guerguerian, F. Elhordoy, C. J. Pereyra, R. E. Marotti, F. Martín, D. Leinen, J. R. Ramos-Barrado and E. A. Dalchiele, Nanotechnology, 2011, 22, 505401.

10 M. Sookhakian, Y. M. Amin, R. Zakaria, S. Baradaran, M. R. Mahmoudian, M. Rezayi, M. T. Tajabadi and W. J. Basirun, Ind. Eng. Chem. Res., 2014, 53, 14301-14309.

11 Z.-S. Wu, S. Yang, Y. Sun, K. Parvez, X. Feng and K. Müllen, J. Am. Chem. Soc., 2012, 134, 9082-9085. 


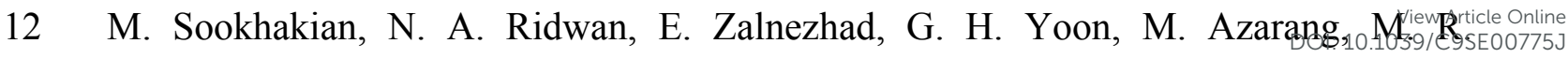
Mahmoudian and Y. Alias, J. Electrochem. Soc., 2016, 163, D154-D159.

13 M. Sookhakian, E. Zalnezhad and Y. Alias, Sensors Actuators, B Chem., 2017, 241, 17.

14 M. Sookhakian, W. J. Basirun, M. A. M. Teridi, M. R. Mahmoudian, M. Azarang, E. Zalnezhad, G. H. Yoon and Y. Alias, Electrochim. Acta, 2017, 230, 316-323.

15 S. N. Faisal, E. Haque, N. Noorbehesht, H. Liu, M. M. Islam, L. Shabnam, A. K. Roy, E. Pourazadi, M. S. Islam and A. T. Harris, Sustain. Energy Fuels, 2018, 2, 2081-2089.

16 S. Wang, L. Zhang, Z. Xia, A. Roy, D. W. Chang, J. B. Baek and L. Dai, Angew. Chemie - Int. Ed., 2012, 124, 4285-4288.

17 S. Baradaran, E. Moghaddam, W. J. Basirun, M. Mehrali, M. Sookhakian, M. Hamdi, M. R. N. Moghaddam and Y. Alias, Carbon N. Y., 2014, 69, 32-45.

18 J. Safaei, H. Ullah, N. A. Mohamed, M. F. M. Noh, M. F. Soh, A. A. Tahir, N. A. Ludin, M. A. Ibrahim, W. N. R. W. Isahak and M. A. M. Teridi, Appl. Catal. B Environ., 2018, 234, 296-310.

19 J. Enkovaara, C. Rostgaard, J. J. Mortensen, J. Chen, M. Dułak, L. Ferrighi, J. Gavnholt, C. Glinsvad, V. Haikola, H. A. Hansen, H. H. Kristoffersen, M. Kuisma, A. H. Larsen, L. Lehtovaara, M. Ljungberg, O. Lopez-Acevedo, P. G. Moses, J. Ojanen, T. Olsen, V. Petzold, N. A. Romero, J. Stausholm-Møller, M. Strange, G. A. Tritsaris, M. Vanin, M. Walter, B. Hammer, H. Häkkinen, G. K. H. Madsen, R. M. Nieminen, J. K. Nørskov, M. Puska, T. T. Rantala, J. Schiøtz, K. S. Thygesen and K. W. Jacobsen, J. Phys. Condens. Matter, 2010, 22, 253202.

20 F. Tran and P. Blaha, Phys. Rev. Lett., 2009, 102, 226401.

21 M. R. Mahmoudian, Y. Alias, W. J. Basirun, P. M. Woi and M. Sookhakian, Sensors Actuators B Chem., 2014, 201, 526-534.

22 C. Ferrante, A. Virga, L. Benfatto, M. Martinati, D. De Fazio, U. Sassi, C. Fasolato, A. K. Ott, P. Postorino and D. Yoon, Nat. Commun., 2018, 9, 308.

23 Y. Feng, Y. Zhang, X. Song, Y. Wei and V. S. Battaglia, Sustain. Energy Fuels, 2017, 1, 767-779. 


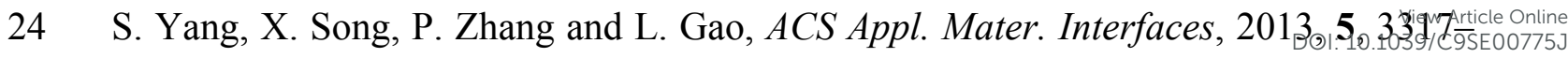
3322.

25 Y. A. Kim, K. Fujisawa, H. Muramatsu, T. Hayashi, M. Endo, T. Fujimori, K. Kaneko, M. Terrones, J. Behrends, A. Eckmann, C. Casiraghi, K. S. Novoselov, R. Saito and M. S. Dresselhaus, ACS Nano, 2012, 6, 6293-6300.

26 J. Luo, H. T. Zhu, H. M. Fan, J. K. Liang, H. L. Shi, G. H. Rao, J. B. Li, Z. M. Du and Z. X. Shen, J. Phys. Chem. C, 2008, 112, 12594-12598.

27 J. Zhu, C. He, Y. Li, S. Kang and P. K. Shen, J. Mater. Chem. A, 2013, 1, 14700-14705.

28 Z. H. Sheng, H. L. Gao, W. J. Bao, F. Bin Wang and X. H. Xia, J. Mater. Chem., 2012, 22, 390 .

29 L. Zhang, Z. Y. Zhang, R. P. Liang, Y. H. Li and J. D. Qiu, Anal. Chem., 2014, 86, 44234430 .

30 J. Qu, L. Shi, C. He, F. Gao, B. Li, Q. Zhou, H. Hu, G. Shao, X. Wang and J. Qiu, Carbon N. Y., 2014, 66, 485-492.

31 H. Osgood, S. V Devaguptapu, H. Xu, J. Cho and G. Wu, Nano Today, 2016, 11, 601625.

32 G. Chen, J. Sunarso, Y. Zhu, J. Yu, Y. Zhong, W. Zhou and Z. Shao, ChemElectroChem, 2016, 3, 1760-1767.

33 S. Ghosh, P. Kar, N. Bhandary, S. Basu, T. Maiyalagan, S. Sardar and S. K. Pal, Int. J. Hydrogen Energy, 2017, 16, 4111-4122.

34 W. Yan, Z. Yang, W. Bian and R. Yang, Carbon N. Y., 2015, 92, 74-83.

35 T. Varga, G. Ballai, L. Vásárhelyi, H. Haspel, Á. Kukovecz and Z. Kónya, Appl. Catal. B Environ., 2018, 237, 826-834.

36 J. Gautam, T. D. Thanh, K. Maiti, N. H. Kim and J. H. Lee, Carbon N. Y., 2018, 137, $358-367$.

37 Y.-Q. Zhang, M. Li, B. Hua, Y. Wang, Y.-F. Sun and J.-L. Luo, Appl. Catal. B Environ., 2018, 236, 413-419.

38 B. Liu, S. Qu, Y. Kou, Z. Liu, X. Chen, Y. Wu, X. Han, Y. Deng, W. Hu and C. Zhong, 
ACS Appl. Mater. Interfaces, 2018, 10, 30433-30440.

39 N. Suo, H. Huang, A. Wu, G. Cao and G. Zhang, Int. J. Hydrogen Energy, 2018, 43, 18194-18201.

40 S. Pan, Z. Cai, L. Yang, B. Tang, X. Xu, H. Chen, L. Ran, B. Jing and J. Zou, Energy, 2018, 159, 11-20.

41 T. Huang, S. Mao, H. Pu, Z. Wen, X. Huang, S. Ci and J. Chen, J. Mater. Chem. A, 2013, 1, 13404-13410.

42 M. R. Mahmoudian, W. J. Basirun, P. M. Woi, H. Hazarkhani and Y. B. Alias, Microchim. Acta, 2019, 186, 349. 
